\title{
Influence of specimen type and reinforcement on measured tension-tension fatigue life
} of unidirectional GFRP laminates

\author{
Korkiakoski, Samuli; Brøndsted, Povl; Sarlin, Essi; Saarela, Olli
}

Published in:

International Journal of Fatigue

Link to article, DOI:

10.1016/j.ijfatigue.2015.12.008

Publication date:

2016

Document Version

Peer reviewed version

Link back to DTU Orbit

Citation (APA):

Korkiakoski, S., Brøndsted, P., Sarlin, E., \& Saarela, O. (2016). Influence of specimen type and reinforcement on measured tension-tension fatigue life of unidirectional GFRP laminates. International Journal of Fatigue, 85, 114-129. https://doi.org/10.1016/j.jifatigue.2015.12.008

\section{General rights}

Copyright and moral rights for the publications made accessible in the public portal are retained by the authors and/or other copyright owners and it is a condition of accessing publications that users recognise and abide by the legal requirements associated with these rights.

- Users may download and print one copy of any publication from the public portal for the purpose of private study or research.

- You may not further distribute the material or use it for any profit-making activity or commercial gain

- You may freely distribute the URL identifying the publication in the public portal 


\section{Influence of specimen type and reinforcement on measured tension- tension fatigue life of unidirectional GFRP laminates}

Samuli Korkiakoskia,*, Povl Brøndsted ${ }^{\mathrm{b}}$, Essi Sarlin ${ }^{\mathrm{c}}$, Olli Saarela ${ }^{\mathrm{a}}$

${ }^{\mathrm{a}}$ Aalto University, School of Engineering, Department of Applied Mechanics, P.O. Box 14300, FI-00076 Aalto, Finland

${ }^{\mathrm{b}}$ Department of Wind Energy, Section of Composites and Materials Mechanics, Technical University of Denmark, Ris $\emptyset$ Campus, Frederiksborgvej 399, DK-4000 Roskilde, Denmark

${ }^{\mathrm{c}}$ Tampere University of Technology, Department of Materials Science, P.O. Box 589, FI-33101 Tampere, Finland

\section{Abstract}

It is well known that standardised tension-tension fatigue test specimens of unidirectional (UD) glassfibre-reinforced plastics (GFRP) laminates tend to fail at end tabs. The true fatigue life is then underestimated. The first objective of this study was to find for UD GFRP laminates a test specimen that fails in the gauge section. The second objective was to compare fatigue performance of two laminates, one having a newly developed UD powder-bound fabric as a reinforcement and the other having a quasiUD stitched non-crimp fabric as a reinforcement. In the first phase, a rectangular specimen in accordance with the ISO 527-5 standard and two slightly different dog-bone shaped specimens were evaluated by means of finite element modelling. Subsequent comparative fatigue tests were performed for the laminates with the three specimen types. The results showed that the test specimen type has a significant effect on the failure mode and measured fatigue life of the laminates. A significantly higher fatigue life was measured for the laminate with the powder-bound fabric reinforcement when compared to the laminate with the stitched reinforcement.

Keywords: Fatigue test methods, Polymer matrix composites, Specimen design, S-N curves, Unidirectional laminate

\footnotetext{
*Corresponding author. Tel.: +358504353762

Email address: samuli.korkiakoski@aalto.fi (Samuli Korkiakoski)
}

\section{Introduction}

Unidirectional (UD) Non-Crimp Fabrics (NCFs) are nowadays widely used as a reinforcement, especially in the spar caps of wind turbine rotor blades [1]. NCFs are fabricated from UD fibre bundles by joining them together with stitch threads. Stitching parameters particularly affect the formability, permeability [2] and compressibility of the fabric [3]. The advantage of NCFs over conventional woven fabrics is a reduced through-thickness crimp, which leads to enhanced mechanical properties [4]. However, stitching also results in a slight fibre waviness [5] that weakens the fatigue properties of laminates. A corresponding non-stitched UD fabric with good handling properties and excellent permeability to resin has recently been developed especially for the manufacture of spar cap laminates of 
wind turbine blades, automotive parts, and boats [6]. This fabric has been formed by joining fibre bundles together with a thermoplastic binder. Single monofilament threads aligned to specified directions are added to the fabric to successfully open a set of infusion pathways in the manufacture of composite parts with a vacuum infusion method. This type of reinforcement provides superior fibre alignment when compared to the stitched NCFs.

Investigating the uni-axial fatigue performance of UD glass-fibre-reinforced plastics (GFRP) laminates is a burdensome and time-consuming process. Nevertheless, fatigue properties of the laminates need to be known, since they are often subjected to uni-axial cyclic loads. Spars caps of wind turbine blades, for instance, are designed to have a service life of 20-25 years, which practically means more than $10^{8}$ load cycles [1], [7], [8], [9], [10]. Thus, long-term durability, that is, preventing fatigue failure, is one of the most important issues within the design process of the wind turbine blades.

It is widely known that tab failure occurs quite regularly when testing uni-axial tension-tension fatigue performance of UD GFRP laminates with rectangular test specimens [11], [12], [13], [14]. The fatigue life is then underestimated for the laminates, and the effect of different UD fabric architectures, for example the effect of NCF stitching parameters may not be found. The specimens should break in the gauge section to obtain the true fatigue performance of the laminates. Failure in the grip area shows that the stresses in the tabs and gripping areas are more detrimental and lead to earlier failure for the test specimens than the uni-axial stresses of the laminate in the gauge section do.

It has been reported [14] that using a waist-shaped (dog-bone) test specimen gives improved fatigue life results especially for UD laminates. The aim of using dog-bone geometry is to reduce the risk of failures in the tabs and gripping areas, i.e., to promote failure in the gauge section. However, the dogbone specimens may split in the longitudinal direction from the edges of the curved area due to low shear resistance of the UD laminates, causing premature failure of the specimen. If the gradual curvature of the specimen is high, the risk of longitudinal splitting along the fibres increases at the edges. Thus, there is a need to find a test specimen geometry with high splitting resistance to obtain the true or at least close to true fatigue life for UD and quasi-UD laminates.

The dog-bone test specimens have often been used in uni-axial tensile fatigue testing of various GFRP laminates. Mandell and Samborsky [15] used dog-bone specimens in their early studies, observing that the failure mode depends on the relative amount of $0^{\circ}$ fibres. A large amount of fatigue test data for 
various UD laminates has been collected for the wind turbine industry in the European OPTIMAT project [16], in which a dog-bone specimen and many different rectangular specimens have been used. However, no mention of any correctly failed specimens can be found in the OPTIMAT database [16]. Qian [17] used a dog-bone geometry with tapered end tabs in fatigue tests of UD laminates. Unfortunately, the specimens usually failed at the end tabs. Aono et al. [18] used a high curvature, double-notched specimen (notched in both thickness and width direction) to investigate damage development in UD laminates. However, they have not reported how the specimens failed. Zangenberg [14] used a dog-bone specimen, almost similar to the one used in this study, and a rectangular specimen (ISO 527-4) to test fatigue performance of UD laminates by subjecting the specimens only to one stress level. Both the dog-bone and rectangular specimens failed outside the gauge section. However, the dog-bone specimen provided a slightly higher fatigue life.

The first objective of this study was to find a suitable dog-bone specimen configuration for UD and quasi-UD GFRP laminates so that the specimens would fail in the gauge section in uni-axial tensiontension fatigue tests. The second objective was to measure the tension-tension fatigue performance and to identify failure modes for two laminates, one having a newly developed UD powder-bound fabric as a reinforcement and the other having a quasi-UD stitched non-crimp fabric as a reinforcement. Finite element analysis was used to evaluate the stress state in a rectangular test specimen in accordance with the ISO 527-5 standard and in two slightly different dog-bone shaped test specimens. Test laminates and specimens were then manufactured and fatigue tested. Digital photography and thermal imaging were used during the tests to detect damages in the gauge section for all the specimens. In addition, longitudinal strain was recorded for some dog-bone specimens to reveal possible stiffness degradation in the gauge section. The tests were performed partly in Aalto University, Finland (later laboratory I) and partly in Technical University of Denmark (later laboratory II).

\section{Materials and methods}

\section{$2.1 \quad$ Test laminate manufacture}

The glass-fibre reinforcements used in the study were a newly developed UD powder-bound fabric (later powder-bound fabric) and a quasi-UD stitched NCF (later stitched fabric) supplied by Ahlstrom Glassfibre Oy. The fabrics were produced from the same batch of the OCV SE1500 Advantex® glassfibre roving. The nominal diameter of the glass fibres was $17 \mu \mathrm{m}$. The detailed glass-fibre properties can 
be found in ref. [19]. The powder-bound fabric has a total areal weight of $1181 \mathrm{~g} / \mathrm{m}^{2}$. The stitched fabric was manufactured using a tricot stitch pattern and normal stitch tension. The total areal weight of the stitched fabric was $1200 \mathrm{~g} / \mathrm{m}^{2}$. The general properties of the fabrics are shown in Table 1 and Table 2. EPIKOTE RIMR135 epoxy resin and RIMH137 hardener supplied by Momentive were used as a resin system to produce the test laminates.

Table 1. Details of the UD powder-bound fabric used in the study.

\begin{tabular}{llll}
\hline Construction & Axial fibres & Binder & Filament \\
\hline Material type & E-glass & Thermoplastic & Synthetic \\
Orientation $\left[{ }^{\circ}\right]$ & 0 & - & - \\
Areal weight $\left[\mathrm{g} / \mathrm{m}^{2}\right]$ & 1152 & 25 & 4 \\
Linear yarn density $[\mathrm{tex}]$ & 2400 & - & - \\
\hline
\end{tabular}

Table 2. Details of the quasi-UD stitched non-crimp fabric used in the study.

\begin{tabular}{llll}
\hline Construction & Axial fibres & Backing fibres & Stitching thread \\
\hline Material type & E-glass & E-glass & Polyester \\
Orientation $\left[{ }^{\circ}\right]$ & 0 & 90 & - \\
Areal weight $\left[\mathrm{g} / \mathrm{m}^{2}\right]$ & 1152 & 36 & 12 \\
Linear yarn density $[$ tex $]$ & 2400 & 68 & 7.6 \\
\hline
\end{tabular}

The laminate panels were produced by vacuum infusion between two heated glass plates $\left(30^{\circ} \mathrm{C}\right)$. The vacuum pressure was $0.93 \mathrm{bar}$, and the infusion was conducted perpendicular to the $0^{\circ}$ fibres. A stacking sequence of $\left[0^{\circ}\right]_{2}$ was used both for the powder-bound and stitched fabric reinforced laminate panels. To reduce voids, the resin/hardener mix was degassed for 10-15 min in a degassing chamber to evacuate dissolved gases from the mix prior to infusion. When the infusion was complete, the vacuum pressure was decreased to 0.3 bar for at least 24 hours. The panels were then post-cured in an oven at $80{ }^{\circ} \mathrm{C}$ for 10 hours as proposed by the resin manufacturer. Five panels reinforced with the powder-bound fabric and two panels reinforced with the stitched fabric were manufactured for the study.

\subsection{Laminate characterisation}

\subsubsection{Fibre weight fractions and fibre volume fractions}

Fibre weight fraction was determined for the test laminates with the resin burn-off technique (ignition loss). The samples of approximately $2 \mathrm{~g}$ were burned in an oven by increasing the temperature slowly to $700{ }^{\circ} \mathrm{C}$. The samples were taken from the laminate panels next to the ends of the fatigue test specimens at 
the same location where the gauge sections of the specimens were located relative to the transverse direction of $0^{\circ}$ fibres. The width of the samples was equal to the width of the test specimens in the gauge section $(15 \mathrm{~mm})$. A total of 49 samples were measured for the powder-bound fabric reinforced laminates and 12 samples for the stitched fabric reinforced laminates. Fibre and resin densities of $2.62 \mathrm{~g} / \mathrm{cm}^{3}$ and $1.15 \mathrm{~g} / \mathrm{cm}^{3}$, respectively, were used for calculating the fibre volume fractions.

\subsubsection{Dynamic mechanical thermal analysis}

Dynamic mechanical thermal analysis was performed to determine the degree of cure of the post-cured laminate panels, that is, to ensure that each panel was properly cured [21]. The glass transition temperatures, $T_{g}$, from the loss modulus peak were measured by using a Perkin Elmer Pyris Diamond apparatus. A minimum of one test sample with dimensions of approximately 4 x $40 \mathrm{~mm}^{2}$ was taken from each panel. Testing was conducted in a single cantilever mode at a frequency of $1 \mathrm{~Hz}$ and with the temperature ramp rate of $3^{\circ} \mathrm{C} / \mathrm{min}$ from $25^{\circ} \mathrm{C}$ to $200{ }^{\circ} \mathrm{C}$.

\subsection{Test specimens}

\subsubsection{Geometry}

A well-known and frequently used rectangular test specimen according to the ISO 527-5:2009 standard [20] was used as a reference specimen in the study. The standard recommends that the tabs should have a length of over or equal to $50 \mathrm{~mm}$, the angle of the end tab edge should be $90^{\circ}$, and the jaws should overhang the end tab area. Also, the end tab material should preferably be made of cross-ply glassreinforced laminate, with the fibres at $\pm 45^{\circ}$ to the specimen axis. Fig. 1a presents the dimensions of the rectangular specimen with $\pm 45^{\circ}$ GFRP end tabs used in this study.

As a relatively high stress concentration exists at the end tab area of the rectangular test specimen, due to the shape of the specimen and specimen clamping, a waisted (dog-bone) specimen geometry was applied as an alternative to decrease the stress concentration. A long specimen with a low curvature was used to keep shear stresses low at the edges of the specimen, i.e., to prevent longitudinal splitting of the laminate at the specimen edges. Long tapered end tabs were further used to obtain a low stress concentration factor at the end tab area and to reduce the risk of end tab delamination.

Two slightly different dog-bone shaped test specimens, A and B, were used in the study. Specimen A (Fig. 1b.) is based on previous investigations [14], in which the dog-bone specimen has been found to 
yield higher fatigue lives than the rectangular specimen. When compared to specimen A, specimen B was developed to lower shear stresses at the specimen edges and to reduce the risk of delamination between the tabs and the laminate. Several FE-analyses and fatigue tests were carried-out with different curvature, spacing of the end tabs and taper angle of specimens to decide on the final values for the geometry parameters. Specimen B (Fig. 1c) differs in geometry from specimen A in terms of lower curvature, longer tab tapering and shorter spacing of the end tabs. The length of the gauge section was $60 \mathrm{~mm}$ and the width of the gauge section was $15 \mathrm{~mm}$ in both specimens.

a)
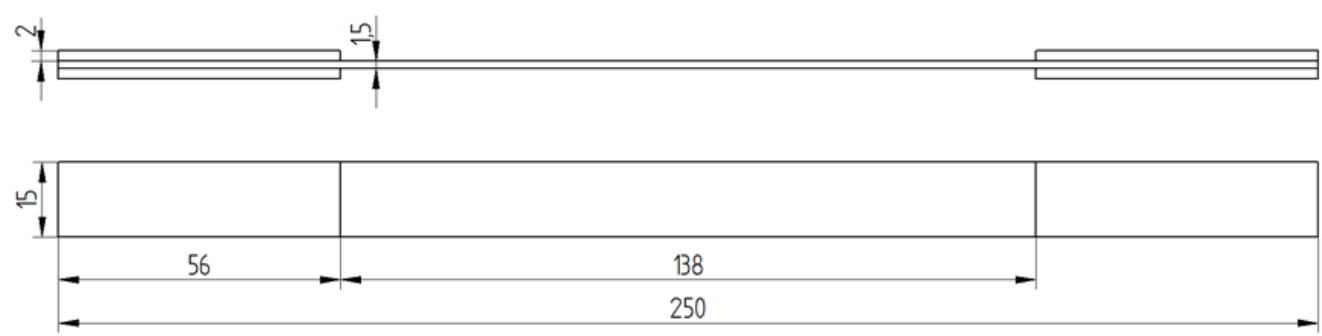

b)
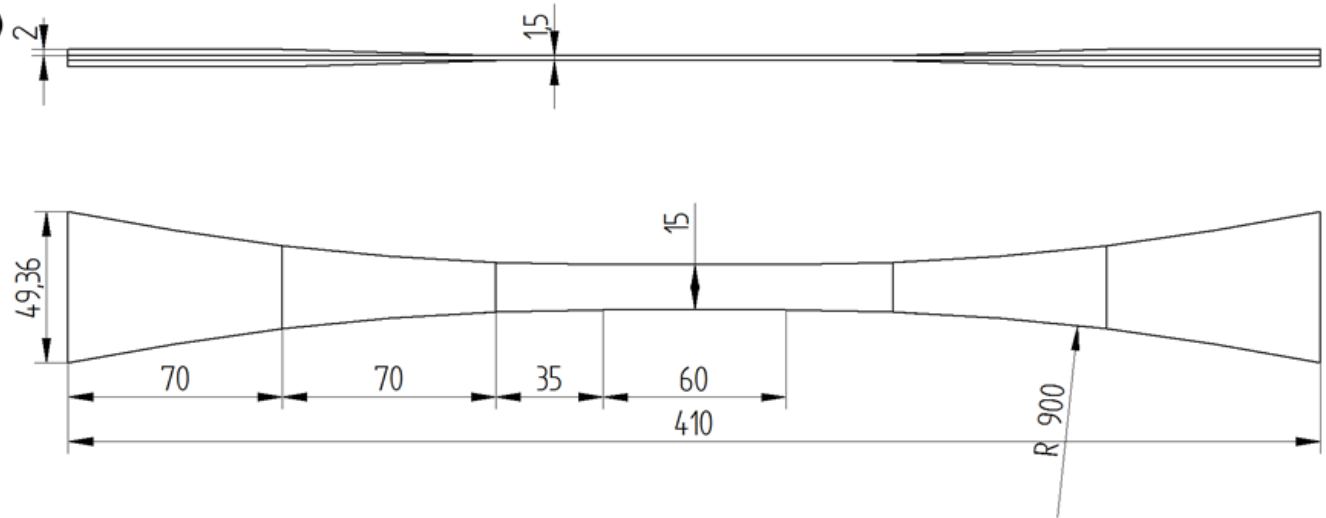

c)
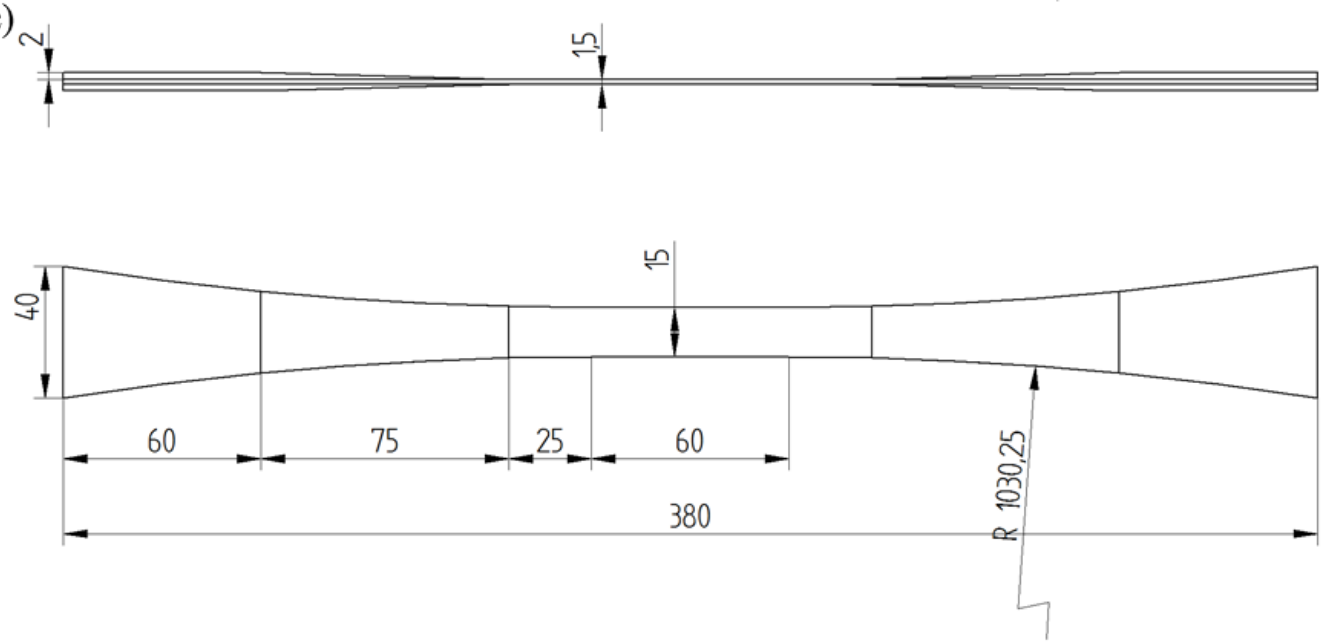

Figure 1. Dimensions of a) ISO 527-5:2009, b) dog-bone A and c) dog-bone B test specimens. 


\subsubsection{Manufacture}

The cross-ply glass-reinforced laminate for the end tabs of the rectangular and dog-bone B specimens was fabricated by vacuum infusion at 0.5 bar vacuum pressure. The cross-ply laminate was formed from nine Hexforce 1202 uniform twill weave layers $\left(290 \mathrm{~g} / \mathrm{m}^{2}\right)$ with a stacking sequence of $[0,90,0,90,0]_{\mathrm{so}}$. Araldite/Aradur 5052 epoxy resin system was used as a matrix material. The laminate was cured at room temperature for 24 hours and later 15 hours at $50{ }^{\circ} \mathrm{C}$. Prior to the bonding of end tabs, the end tab and test laminate surfaces to be bonded were grit-blasted with aluminium oxide and cleaned with MEK (methyl ethyl ketone) to improve adhesion and to minimise the risk of delamination between the tab and test laminate during fatigue testing. The tabs with the fibres at $\pm 45^{\circ}$ to the specimen axis were bonded using structural epoxy adhesive (3M, DP190). A thin nylon scrim cloth layer was used in the bond line to control the adhesive thickness. The specimens were put in a vacuum bag and 0.8 bar vacuum pressure was applied for 24 hours. Later, the specimens were post-cured at $45^{\circ} \mathrm{C}$ for 2 days. The rectangular specimens were obtained by cutting the laminates with a diamond-blade-equipped cutting machine and the specific shape of the dog-bone specimens was CNC machined. Tab tapers were ground next to the gauge section area of the dog-bone B specimens by using a belt grinding machine. Laminate-end tab junctions were manually smoothed with sandpaper. Finally, the edges of the specimens were sanded and polished with P240, P400, P800, P1200 and P2000 grit-sized sandpapers to achieve smooth surfaces.

The cross-ply glass-reinforced epoxy laminates for the end tabs of the dog-bone A specimens were 2 $\mathrm{mm}$ thick, prefabricated laminates (Electro-Isola, G-Etronax EP11). They were machined to the required tapering angle (Fig. 1b). The tab laminates consisted of ten \pm 45 aligned E-glass fabrics with plain weave $\left(230 \mathrm{~g} / \mathrm{m}^{2}\right)$ and of high glass-transition temperature epoxy resin $\left(\sim 165^{\circ} \mathrm{C}\right)$. The UD laminate was cut to the required length $(410 \mathrm{~mm})$. After cutting, the tab sections of the UD laminate were blasted with glass particles in order to open the surfaces for optimal adhesion. The end tab laminates were cleaned with ethanol and bonded to the test laminates by using a two-component epoxy adhesive (3M, DP460). The end tabs with fibres at $\pm 45^{\circ}$ to the UD laminate $0^{\circ}$ axis were fixed and pressurised with clamps to the test laminate and cured for $16-24$ hours at $40{ }^{\circ} \mathrm{C}$. The specimens were cut to the desired geometry by using a CNC cutting machine. The edges of the specimens were smoothed similarly to the dog-bone B specimens. 
The specimens were modelled by using the Solid Edge software. The parts were then imported to the software ABAQUS ${ }^{\mathrm{TM}} / \mathrm{Standard}$ v6.14-1 for a finite element (FE) analysis. Half of the specimens were modelled to reduce the calculation time. Simplified models were used so that the effect of the gripping pressure and the adhesive layer in between the end tabs and the laminate were ignored. The thickness of the UD laminate was set to $1.5 \mathrm{~mm}$, representing a laminate manufactured of two UD fabrics. The interaction between the laminate and the end tabs was modelled by using a tie constraint with surface-tosurface discretization. Fig. 2a illustrates the model for the rectangular specimen and Fig. $2 b$ for the two dog-bone specimens.

The specimen models were meshed with a mesh size of approximately $1 \mathrm{~mm}$, using C3D20R quadratic brick elements with reduced integration. For the rectangular specimen, where higher stress concentrations were expected, the element size was reduced to $0.5 \mathrm{~mm}$ close to the tab edges. The longitudinal displacement was set to zero $\left(\mathrm{u}_{1}=0\right)$ on plane $\mathrm{A}$ and transverse displacements were set to zero $\left(\mathrm{u}_{2}=0\right.$ and $\mathrm{u}_{3}=0$ ) on planes B (see Fig. 2). A tensile stress of $600 \mathrm{MPa}$ was applied on plane C, since most of the subsequent fatigue tests were performed at or near this stress level. The absolute value of this stress is, however, not important, since the simulation was linear-elastic and the width of the gauge section was the same in all specimens. The elastic properties of the specimens were defined by giving engineering constants for the laminate (quasi-UD laminate manufactured from NCFs) and end tabs as an input. Table 3 provides the material data used for the laminate and for the $\pm 45^{\circ}$ aligned woven-fabric epoxy end tab laminate. Longitudinal $\left(\sigma_{11}\right)$, transverse $\left(\sigma_{22}\right)$ and shear $\left(\sigma_{12}\right)$ stress distributions were compared in order to evaluate the effect of specimen geometry on the stress field. The stress concentration factor SCF $=$ max $\sigma_{11} / \sigma_{\text {applied }}$ was also computed and compared between the specimens. 


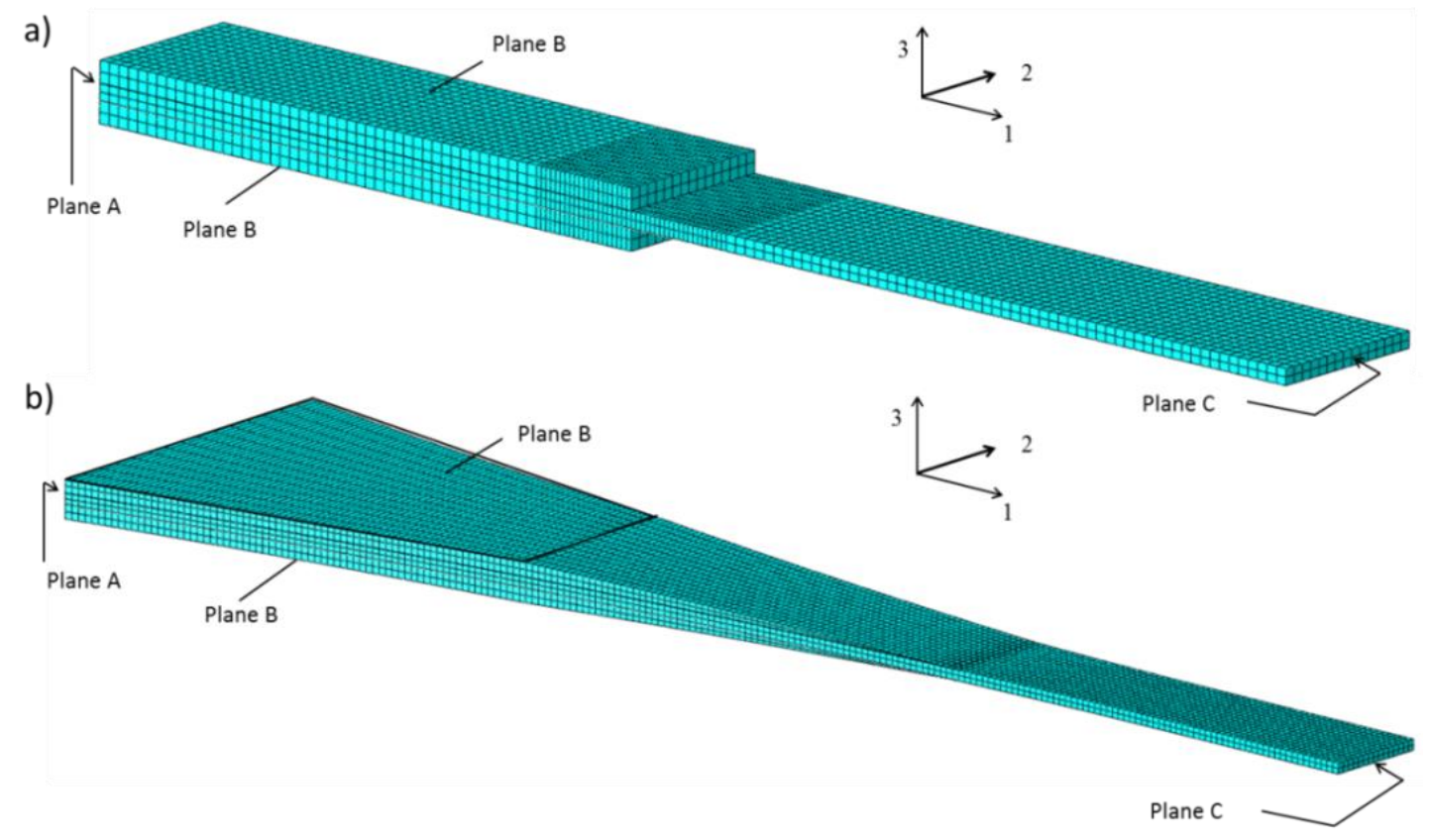

Figure 2. Coordinate systems, boundary conditions and element meshes used in the half model of the a) rectangular specimen and b) dog-bone specimens.

Table 3. Laminate engineering constants used in finite element analyses.

\begin{tabular}{llllllllll}
\hline $\begin{array}{l}\text { Type of } \\
\text { laminate }\end{array}$ & $\begin{array}{l}\text { E11 } \\
{[\mathrm{GPa}]}\end{array}$ & $\begin{array}{l}\mathrm{E} 22 \\
{[\mathrm{GPa}]}\end{array}$ & $\begin{array}{l}\mathrm{E} 33 \\
{[\mathrm{GPa}]}\end{array}$ & $\begin{array}{l}v 12 \\
{[-]}\end{array}$ & $\begin{array}{l}v 13 \\
{[-]}\end{array}$ & $\begin{array}{l}v 23 \\
{[-]}\end{array}$ & $\begin{array}{l}\mathrm{G} 12 \\
{[\mathrm{GPa}]}\end{array}$ & $\begin{array}{l}\mathrm{G} 13 \\
{[\mathrm{GPa}]}\end{array}$ & G23 \\
\hline UD laminate [22] & 44 & 17 & 16.7 & 0.262 & 0.264 & 0.35 & 3.49 & 3.77 & 3.46 \\
End tab [24] & 13.89 & 13.89 & 10 & 0.544 & 0.178 & 0.178 & 12.46 & 4 & 4 \\
\hline
\end{tabular}

\section{$2.5 \quad$ Quasi-static tests}

Quasi-static uni-axial tensile tests were performed for all the specimens to determine the initial tensile modulus prior to fatigue tests. The thickness and width of the gauge section were measured at three points and the average values were used to calculate the cross-sectional area. The test was stopped when a predefined stress level was achieved in the gauge section of the specimen. The load rate of $7 \mathrm{kN} / \mathrm{min}$ was used for all specimens. At laboratory I, the tests were performed on a servo-hydraulic Dartec testing machine with hydraulic wedge grips, a load cell of $100 \mathrm{kN}$, and an MTS controller. The strain was measured continuously with an MTS extensometer with a $50 \mathrm{~mm}$ gauge length. The tensile modulus of each specimen was calculated from the slope of the strain-stress curve between the points of 0.001 and $0.003 \mathrm{~m} / \mathrm{m}$.

Part of the dog-bone A and B specimens were tested at laboratory II. These tests were carried out as certified tests according to DANAK accreditation 210 and performed on $88 \mathrm{R} 8501$ test machine with a load cell of $100 \mathrm{kN}$. The specimens were clamped with hydraulic grips. Strain was measured by using two 
back-to-back mounted extensometers with a gauge length of $50 \mathrm{~mm}$. The initial tensile modulus was measured and calculated according to ISO $527-5$ between the points of 0.0005 and $0.0025 \mathrm{~m} / \mathrm{m}$.

\subsection{Fatigue tests}

Fatigue tests were performed with the same equipment as the quasi-static tests. A constant load amplitude, sinusoidal wave-form uni-axial tension-tension fatigue test with the stress ratio $\mathrm{R}=0.1$ was performed on each specimen after the quasi-static test. Each fatigue test was performed in the load control mode directly at the load level (stress) applied for the modulus determination (Section 2.5) and was stopped after complete failure of the specimen. The test frequency of $4 \mathrm{~Hz}$ was mainly used to avoid excessive heating of the specimens. The ISO 13003:2003(E) standard states that the test frequency shall be chosen to avoid an excessive temperature rise in the specimen surface up to $10{ }^{\circ} \mathrm{C}$ during the tests [25]. At laboratory, II strain was measured throughout the full fatigue tests using the same back-to-back mounted extensometers as used in the quasi-static tests.

\subsection{Damage characterisation}

\subsubsection{Stiffness degradation}

Resulting from progressive damage accumulation, composite materials normally undergo stiffness degradation during fatigue tests [26], [27]. Therefore, the longitudinal strain was monitored continuously during the fatigue tests for specimens tested at laboratory II. The stiffness in the gauge section was calculated for each fatigue cycle as the slope of the full hysteresis loop, i.e., the stiffness was defined as the ratio of the laminate fatigue stress and strain range. Also, the distance between upper and lower grips was monitored during the fatigue tests. The overall stiffness between the grips was calculated as the ratio of the applied load and displacement range from the displacement-load hysteresis loop.

\subsubsection{Digital photography and thermal imaging}

The gauge section of each specimen was photographed during the quasi-static and fatigue tests at laboratory I to monitor the initiation and development of cracks. Due to the very smooth surfaces of the laminates and the very transparent nature of the matrix and glass fibres, the gauge sections of the specimens were extraordinarily transparent. Thus, matrix cracks, fibre breakages and voids could be observed. Individual glass fibres could not be seen, while stitch threads in the stitched fabric reinforced 
laminates and monofilaments in the powder-bound fabric reinforced laminates remained visible. Digital images were taken using a Canon SX30 IS digital camera.

The specimens were also investigated during the fatigue tests by means of thermal imaging to monitor heat development in the specimens' gauge section. The thermal images were taken with a Fluke Ti32 infrared thermal imaging camera.

Digital and thermal images were taken for pristine specimens, after the quasi-static tests, and also during the fatigue tests after 1000,5000 and 10000 cycles and later usually after intervals of 10000 cycles.

\subsection{Statistical analyses of fatigue test results}

Fatigue data was analysed by plotting $S$ - $N$ curves on a conventional linear-logarithmic graph (Wöhler diagram). The relationship between the applied peak stress and the number of cycles to failure was used with the power-law regression model equation (Basquin 1910) to analyse the fatigue data:

$$
N=C \cdot S^{m}
$$

In Eq. (1), $S$ is the maximum applied stress, $C$ is the intercept parameter, $N$ is the measured fatigue life and $m$ is the slope of the $S$ - $N$ curve. Eq. (1) yields a linear $S$ - $N$ curve on a log-log graph. The least-squares method was used to obtain values of the parameters $C$ and $m$ according to the ASTM E 739 standard using the number of cycles as a dependent variable and the stress as an independent variable [28]. The coefficient of determination $R^{2}$ was defined for each data set to indicate how well the $S$ - $N$ curve fits the regression model.

To statistically analyse the significance of the difference in fatigue lives measured with different types of specimens, a specified regression with fatigue life data analysis was performed with the aid of the program MINITAB [29]. The logarithms of the fatigue lives were assumed to be normally distributed, that is, the fatigue life was assumed to be log-normally distributed. The probability that there is no difference in the fatigue life between two specimens being compared is indicated as the p-value. A $95 \%$ confidence level $(\alpha=0.05)$ was used to compare the difference between specimens; that is, if $\mathrm{p}$ is smaller than 0.05 , the specimen geometry significantly affects the fatigue life. 


\section{Results}

\subsection{Finite element analyses}

The results of the FE analyses are shown in Fig. 3, Fig. 4 and Fig. 5 in the form of the longitudinal, transverse and shear stress distributions. To visualize the UD laminate, the upper end tab is not shown in the figures 3-5 and the lower end tab is displayed in white. Stress concentration factor SCF for the longitudinal stress component along each specimen from the specimen end is presented in Fig. 6.

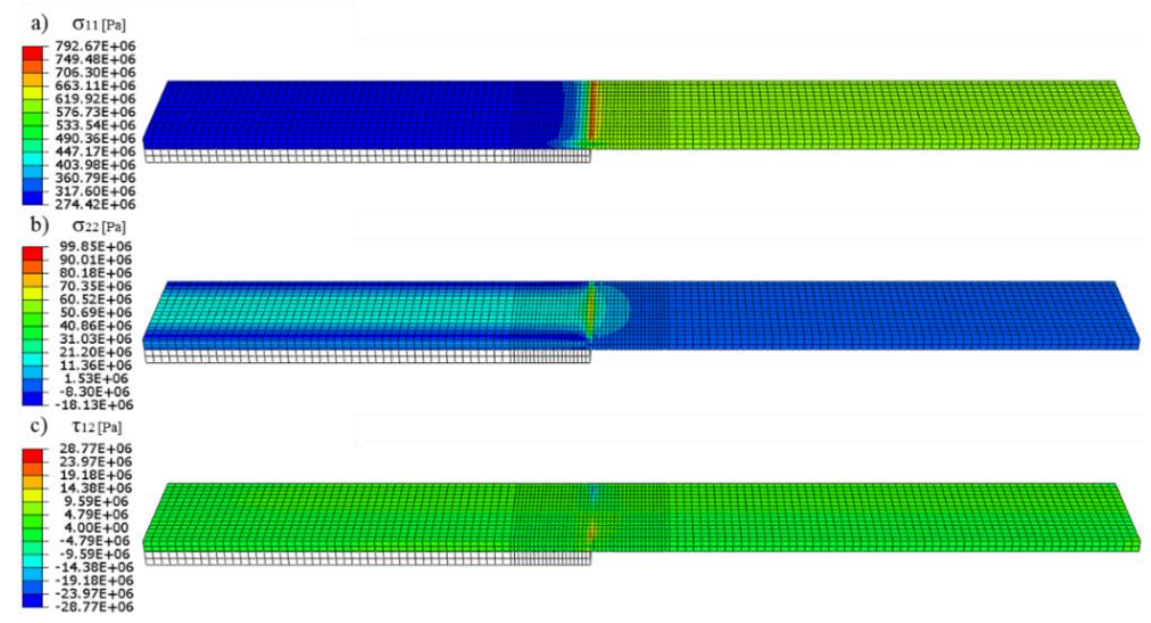

Figure 3. a) Longitudinal, b) transverse and c) shear stress distributions in the rectangular specimen. Upper end tab is ignored in the figures and the lower end tab is displayed in white.

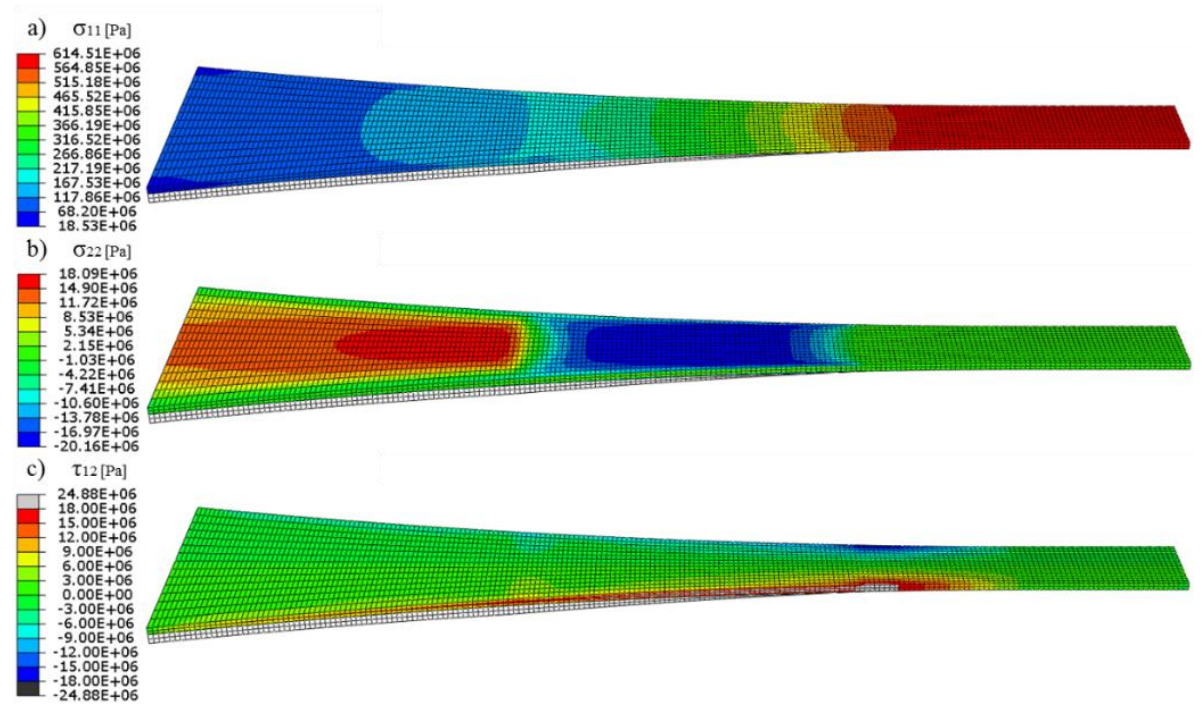

Figure 4. a) Longitudinal, b) transverse and c) shear stress distributions in the dog-bone A specimen. Upper end tab is ignored in the figures and the lower end tab is displayed in white. 


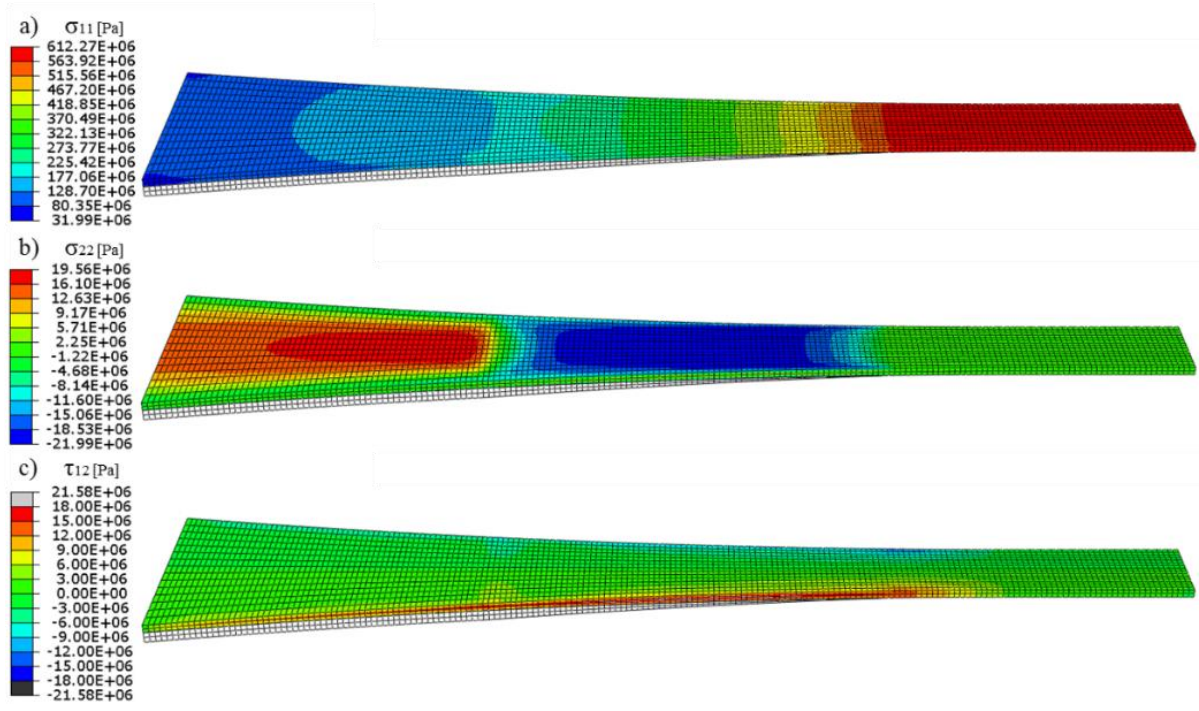

Figure 5. a) Longitudinal, b) transverse and c) shear stress distributions in the dog-bone B specimen. Upper end tab is ignored in the figures and the lower end tab is displayed in white.

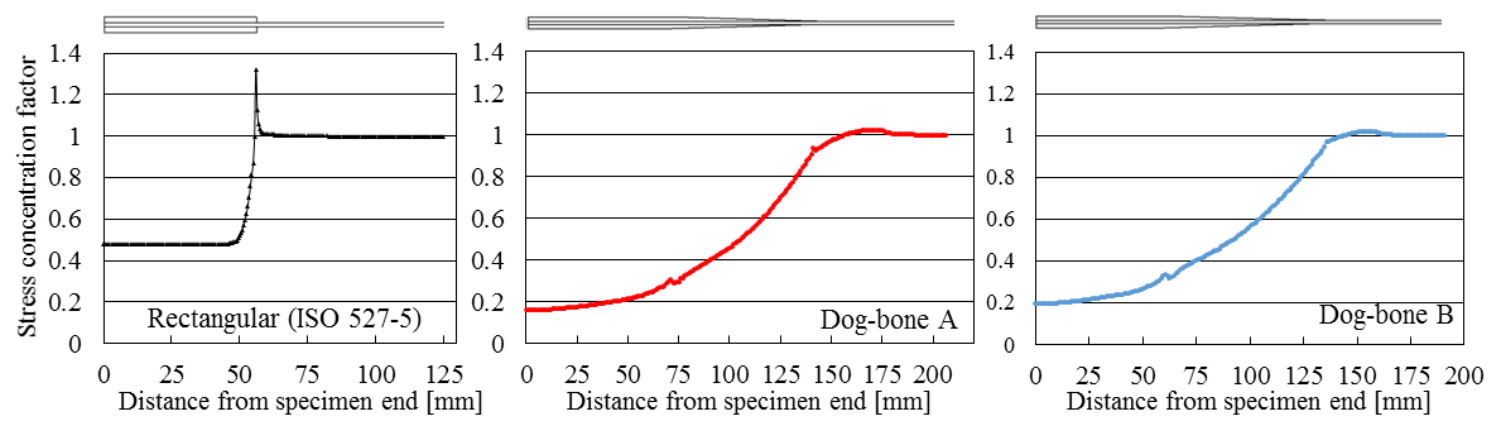

Figure 6. Stress concentration factor along the rectangular and dog-bone specimens from the end of the specimens.

The stress distributions of the rectangular specimen (Fig. 3 a-c) indicate that laminate stresses are highest at the end of the tabs. From the longitudinal stress results in Fig. 3a and Fig. 6, a stress concentration factor SCF of 1.32 was found at the end of the tabs. For the dog-bone A specimen, the stress distributions are shown in Fig. 4 a-c. The stress concentration factor SCF of 1.02 was found at the point where curvature begins outside the tabbed area (see also Fig. 6). The highest shear stress of 24.9 $\mathrm{MPa}$ is located at the edges next to the tab-laminate intersection. For the dog-bone B specimen, the stress distributions are presented in Fig. 5 a-c. The stress concentration factor SCF of 1.02 was found at the point where curvature begins outside the tabbed area (see also Fig. 6). The highest shear stress of 21.6 $\mathrm{MPa}$ is located at the edges of the UD laminate under the end tabs. Additionally, the area of high shear stress is seen to be smaller than in the dog-bone A specimen. The transverse stress distributions of the dog-bone specimens A and B are similar to each other. 
To summarise the results, the computed SCFs are substantially lower for the dog-bone specimens when compared to the rectangular specimen. The results also indicate that small changes in the dog-bone geometry have a clear effect on the maximum shear stress value at the edges of the specimen and on the area with high shear stress. From the two dog-bone specimens, the specimen B provided a smoother stress field.

\subsection{Fibre volume fraction}

The fibre volume fractions (FVF) obtained with the resin burn-off technique for the powder-bound and stitched fabric reinforced laminates were $52.9 \pm 2.2 \%$ and $55.5 \pm 1.3 \%$, respectively (average \pm standard deviation). The stitched fabric thus provided a slightly higher fibre volume fraction. The standard deviations were relatively small for both types of laminates.

\subsection{Glass transition temperatures}

The average glass transition temperatures, $T_{g}$, measured from the loss modulus peak, were $86.1 \pm$ $1.8^{\circ} \mathrm{C}$ and $85.5 \pm 0.4{ }^{\circ} \mathrm{C}$ for the powder-bound and stitched fabric reinforced laminates, respectively. The average $T_{g}$ values were thus similar for the laminates and the standard deviations were low. These results indicate that the laminate panels had an equal degree of cure (presumably $\approx 100 \%$ ).

\subsection{Tensile moduli}

The measured average tensile modulus values and standard deviations for each type of specimen are shown in Table 4 . The average values are seen to be very close to each other, implying that the specimen types used in the study do not have an effect on the measured tensile modulus.

Table 4. Measured tensile moduli for all specimens.

\begin{tabular}{|c|c|c|c|c|c|c|}
\hline & \multicolumn{3}{|c|}{ Powder-bound fabric } & \multicolumn{3}{|c|}{ Stitched fabric } \\
\hline $\begin{array}{l}\text { Type of } \\
\text { specimen }\end{array}$ & $\begin{array}{l}\text { Mean tensile } \\
\text { modulus } \\
{[\mathrm{GPa}]}\end{array}$ & $\begin{array}{l}\text { Standard } \\
\text { deviation } \\
{[\mathrm{GPa}]}\end{array}$ & $\begin{array}{l}\text { Number of } \\
\text { specimens }\end{array}$ & $\begin{array}{l}\text { Mean tensile } \\
\text { modulus } \\
{[\mathrm{GPa}]}\end{array}$ & $\begin{array}{l}\text { Standard } \\
\text { deviation } \\
{[\mathrm{GPa}]}\end{array}$ & $\begin{array}{l}\text { Number of } \\
\text { specimens }\end{array}$ \\
\hline Rectangular & 44.26 & 1.62 & 11 & 44.39 & 0.91 & 10 \\
\hline Dog-bone A & 43.64 & 2.02 & 14 & - & - & - \\
\hline Dog-bone B & 44.60 & 1.32 & 19 & 43.78 & 1.12 & 9 \\
\hline
\end{tabular}

Average modulus values and standard deviations of the moduli were further computed for the powderbound and stitched fabric reinforced laminates by combining the data measured from all specimen types. The modulus values were $44.21 \pm 1.66 \mathrm{GPa}$ and $44.10 \pm 1.03 \mathrm{GPa}$ for the powder-bound and stitched 
fabric reinforced laminates, respectively. Due to the small difference in measured fibre volume fractions between the laminates, linear normalisation of the moduli was done to the fibre volume fraction of $55 \%$. The normalised tensile moduli of the powder-bound and stitched fabric reinforced laminates were $46.27 \pm$ $1.73 \mathrm{GPa}$ and $43.73 \pm 1.02 \mathrm{GPa}$, respectively. The results indicate that after removing the effect of fibre volume fraction by normalisation, the tensile modulus is $5.8 \%$ higher for the powder-bound fabric reinforced laminate. A one-way ANOVA analysis for one factor with two levels was performed to statistically compare the difference of the average normalised tensile moduli. The probability that there is no difference between the two laminates being compared is indicated as the p-value. A $95 \%$ confidence level $(\alpha=0.05)$ was used, meaning that if $p<0.05$, there is a significant difference in the modulus. A pvalue less than 0.001 was obtained, meaning that the difference is statistically significant. This indicates that there is another mechanism than just fibre volume fraction, probably the absence of the stitching thread and backing yarn, resulting in only a negligible fibre undulation in the powder-bound fabric reinforced laminates, which influences the stiffness of the laminates.

\subsection{Failure modes in fatigue loading}

\subsubsection{Powder-bound fabric reinforced laminates}

Each rectangular specimen made from the powder-bound fabric reinforced laminate failed in a catastrophic brittle manner at the end tabs. Significant temperature increase was observed at the end of the tabs during the fatigue loading. No significant observable damages, i.e., matrix cracks, delamination or fibre breakages and associated heat development, were found in the gauge section. An example of the failed rectangular specimen is shown in Fig. 7a.

For the dog-bone A specimens, very small matrix cracks initiated without considerable heat development in the gauge section. However, longitudinal splitting occurred at the edges and subsequent delamination between the laminate and end tab propagated towards the grips, increasing also temperature at the tabbed area and causing finally failure at the end tabs. Fig. $7 \mathrm{~b}$ presents a typical end tab failure of the dog-bone A specimen.

Some dog-bone B specimens failed similarly to the dog-bone A specimens but several dog-bone B specimens seemed to fail in the gauge section, although some of them experienced also splitting and delamination at the tabbed area with minor heat increase. An example of the dog-bone B specimen that failed in the gauge section is shown in Fig. 7c. In the dog-bone B specimens that failed in the gauge 
section, small matrix cracks or fibre/matrix debonds were observed in the gauge section during the test. In addition, some severe damages such as matrix cracks, fibre debonding and fibre breakages, developed in the gauge section usually at the points where single monofilaments were located. These severe damages propagated towards the end tabs, which usually caused the final failure. Damage development in the gauge section of the dog-bone B specimen during the fatigue test is shown in Fig. 8. The white spots represent severe damages that propagated and caused the final failure of the specimen. Fig. 9a illustrates that heat also developed at these spots during the fatigue test, verifying damage accumulation.

To summarise, all rectangular and the dog-bone A specimens and some dog-bone B specimens made from the powder-bound fabric reinforced laminate failed at the end tabs. However, some dog-bone B specimens experienced detrimental damages in the gauge section, which resulted in the final failure of the specimens in the gauge section.
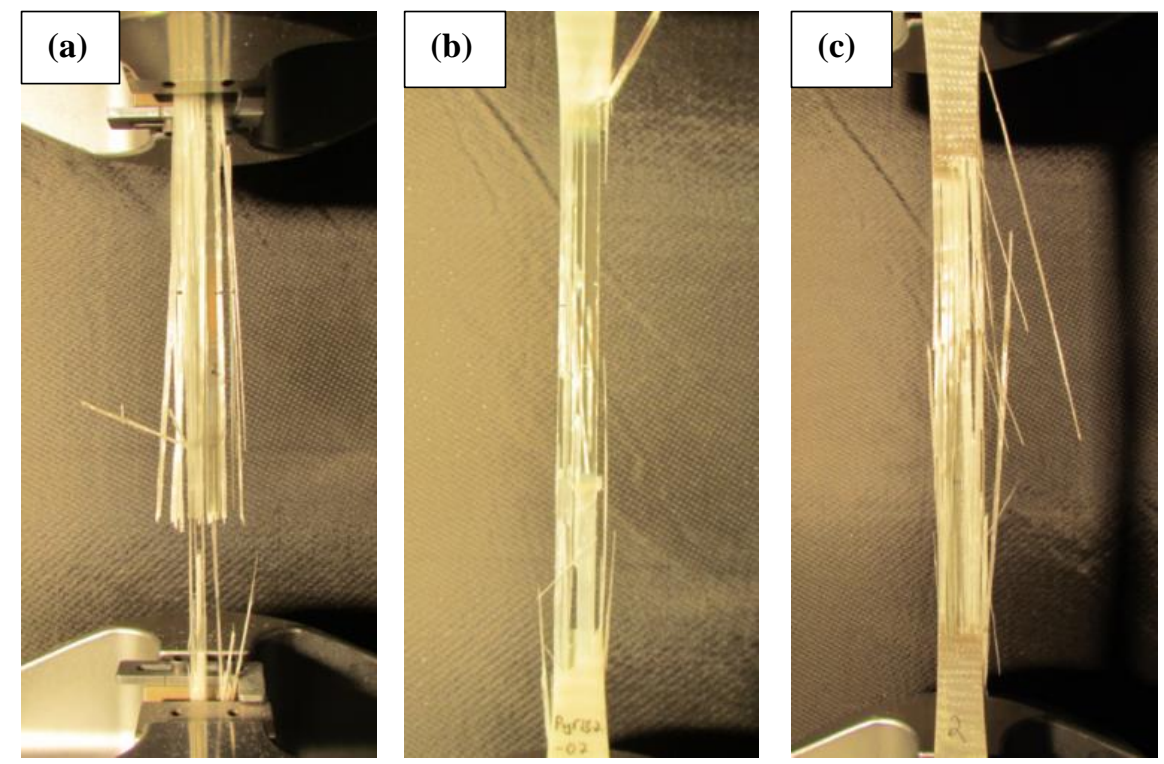

Figure 7. Example of a failed a) rectangular, b) dog-bone A and c) dog-bone B test specimens for the UD powder-bound fabric reinforced laminate at the end of the tensile fatigue test. 


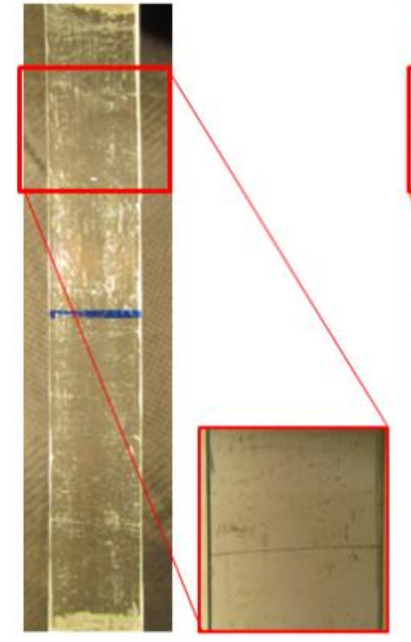

20000 cycles

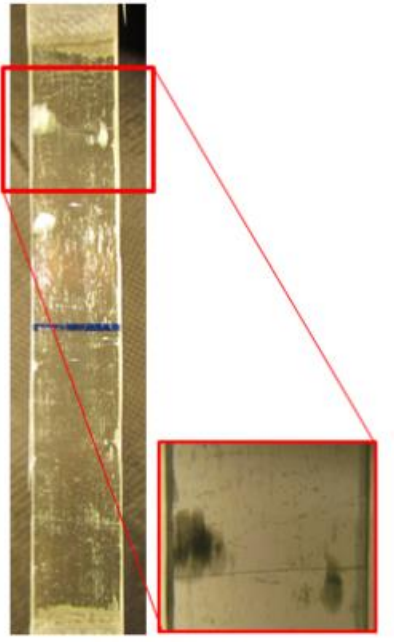

50000 cycles

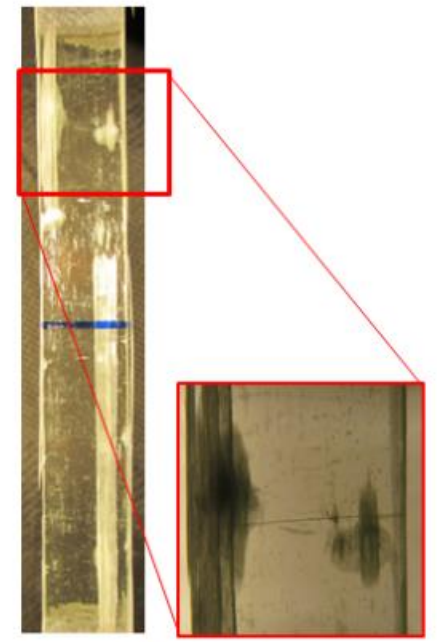

60000 cycles

Figure 8. Typical damage initiation and development in the UD powder-bound fabric reinforced laminate during the tensile fatigue test of the dog-bone B specimen.

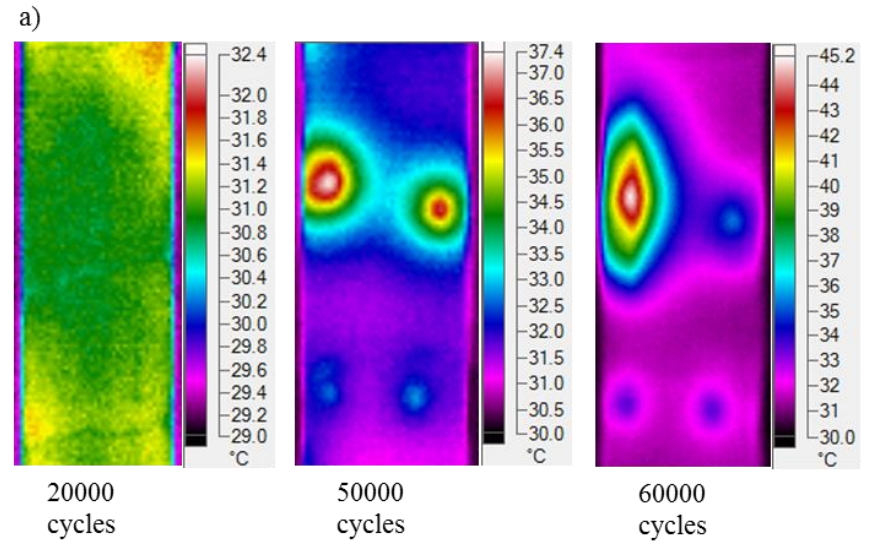

b)

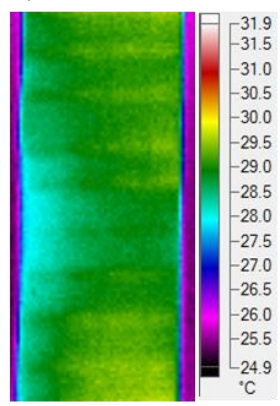

5000

cycles

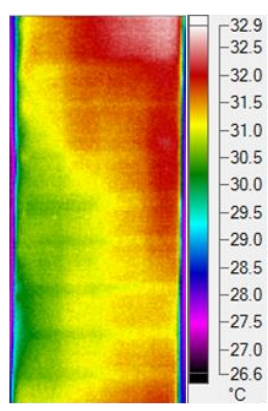

10000

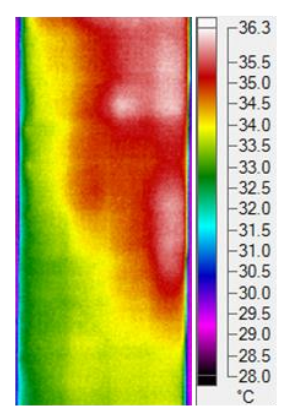

15000

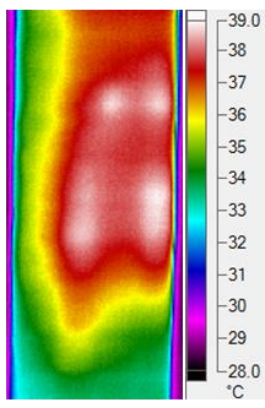

17000

Figure 9. Heat development in a) the UD powder-bound fabric and b) the stitched fabric reinforced laminate during the tensile fatigue test of the dog-bone B specimen.

\subsubsection{Stitched fabric reinforced laminates}

The stitched fabric reinforced laminates were fatigue-tested using only the rectangular and dog-bone B specimens. All rectangular specimens failed close to the end tab area. Photographing and thermal imaging 
revealed that transverse cracks in the backing fibre bundles and a few small axial matrix cracks or fibre/matrix debonds in the fibre bundles developed in the gauge section before the final failure. A failed rectangular specimen is shown in Fig. 10a.

The dog-bone B specimens experienced damages such as transverse matrix cracks, fibre debonding and fibre breakages in the gauge section. Finally, the specimens seemed to fail frequently in the gauge section. An example of a failed dog-bone B specimen is shown in Fig. 10b. Fig. 11 shows typical transverse matrix cracks at the backing bundles and several white spots, in which longitudinal matrix cracks or fibre/matrix debonds in the axial bundles have initiated and developed, also causing axial fibre breakages during the fatigue test. Fig. $9 \mathrm{~b}$ shows the extensive heat development at the same white spots where the damages occurred in the gauge section.

To summarise, all rectangular specimens made from the stitched fabric reinforced laminate failed at the end tabs. In the dog-bone B specimens damages initiated and propagated in the gauge section, resulting in the final failure in the gauge section.
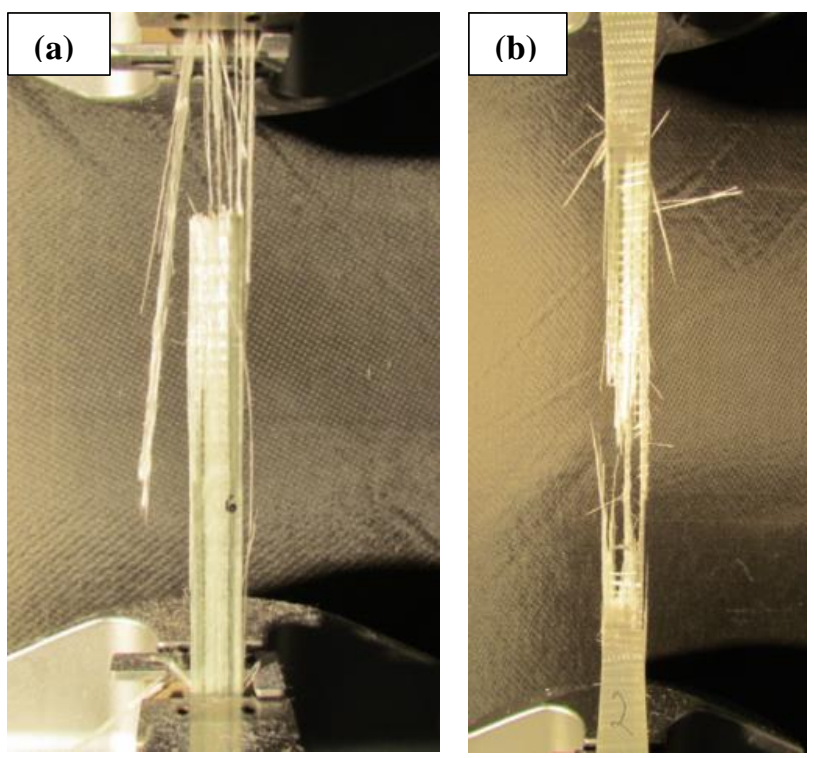

Figure 10. Failed a) rectangular specimen and b) dog-bone B specimen made from the stitched fabric reinforced laminate after the tensile fatigue test. 


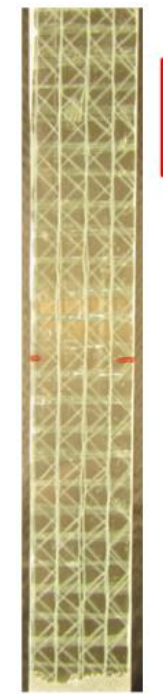

5000

cycles

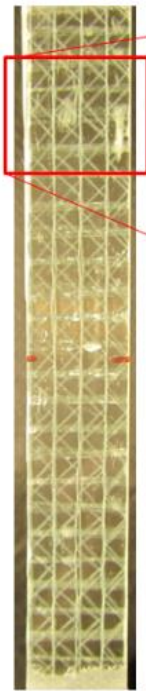

10000

cycles

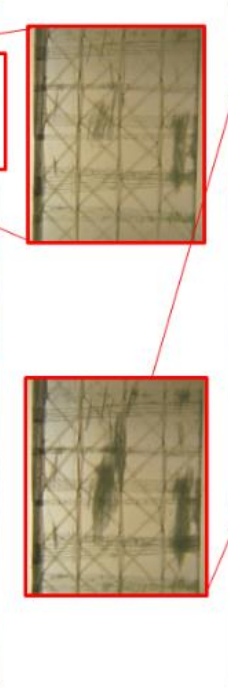

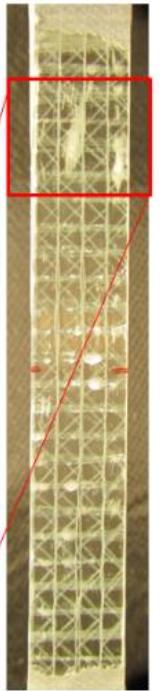

15000

cycles

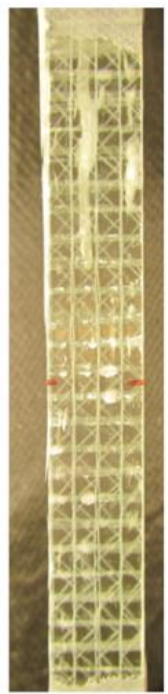

17000

cycles

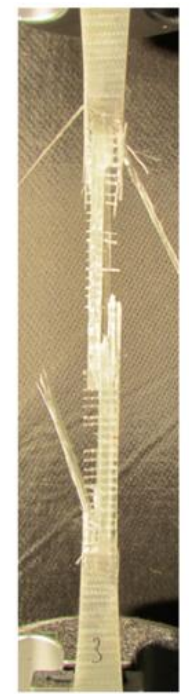

18738 cycles

Figure 11. Typical damage initiation and development in the stitched fabric reinforced laminate during the tensile fatigue test of the dog-bone B specimen.

\subsection{Measured fatigue lives}

\subsubsection{Powder-bound fabric reinforced laminates}

Fatigue tests of the powder-bound fabric reinforced laminate were performed with all specimen types. For the dog-bone A and B specimens, fatigue tests were performed in two laboratories (I and II). S-N curves for both dog-bone specimens tested at relatively high stress levels in laboratory I are presented in Fig. 12a. Fatigue data measured in laboratory II at lower stress levels is shown in Fig. 12b.

Statistical analyses were performed separately for both dog-bone specimens tested at the two laboratories to test the equality of two regressions using 'Testing for Equality of Several Regressions' according to the Military Handbook MIL-HDBK-5H [30]. In the linear case, if F-statistics is greater than the quantiles of the 95th percentile of the F-distribution, the hypothesis that the regressions are equal is rejected. Calculations yielded F-statistics $=0.70$ and $\mathrm{F}_{95}=3.68$ for the dog-bone B specimen and Fstatistics $=1.53$ and $\mathrm{F}_{95}=4.10$ for the dog-bone $\mathrm{A}$ specimen. The results thus indicate that regressions are equal for the dog-bone A and B specimens. Therefore, the test results obtained in both places can be combined into one regression for both specimens. 

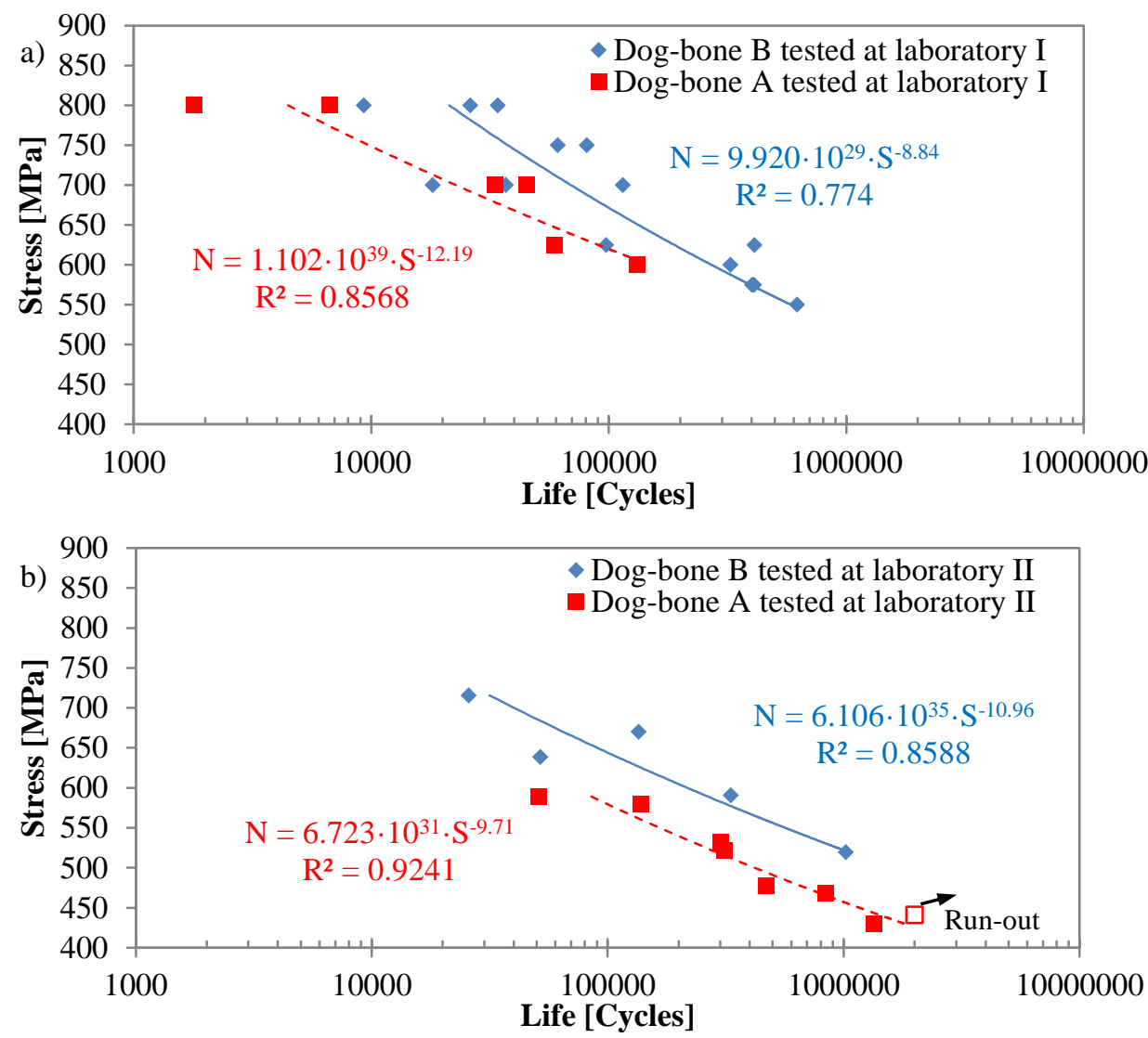

Figure 12. S-N curves of the UD powder-bound fabric reinforced laminate measured with dog-bone A and dog-bone B test specimens, tested a) in laboratory I and b) in laboratory II.

The combined S-N fatigue data measured for the powder-bound fabric reinforced laminate with all specimen types are presented in Fig. 13a. The results show a relatively small scatter $\left(\mathrm{R}^{2}\right.$ values $)$ for the rectangular and dog-bone A specimens but a slightly higher scatter for the dog-bone B specimens. The combined S-N fatigue curves with $95 \%$ confidence bands in accordance with the ASTM E 739 standard are shown in Fig. 13b. The results of the specified regression analysis indicated that the fatigue lives of the rectangular and dog-bone A specimens are significantly different $(\mathrm{p}<0.001)$. Similarly, the fatigue lives of the dog-bone A and B specimens are significantly different $(\mathrm{p}<0.001)$. The S-N curves and corresponding confidence bands indicate that the specimen geometry has a significant influence on the measured fatigue performance. The fatigue life measured with the dog-bone B specimen was over ninefold when compared to the fatigue life measured with the rectangular test specimen and over three-fold when compared to the fatigue life measured with the dog-bone A test specimen, when the specimens were subjected to $600 \mathrm{MPa}$ maximum stress. On the other hand, the stress levels corresponding to a fatigue life of $10^{5}$ cycles were $529 \mathrm{MPa}, 589 \mathrm{MPa}$ and $666 \mathrm{MPa}$ for the rectangular, dog-bone $\mathrm{A}$ and dog-bone $\mathrm{B}$ specimens, respectively. 

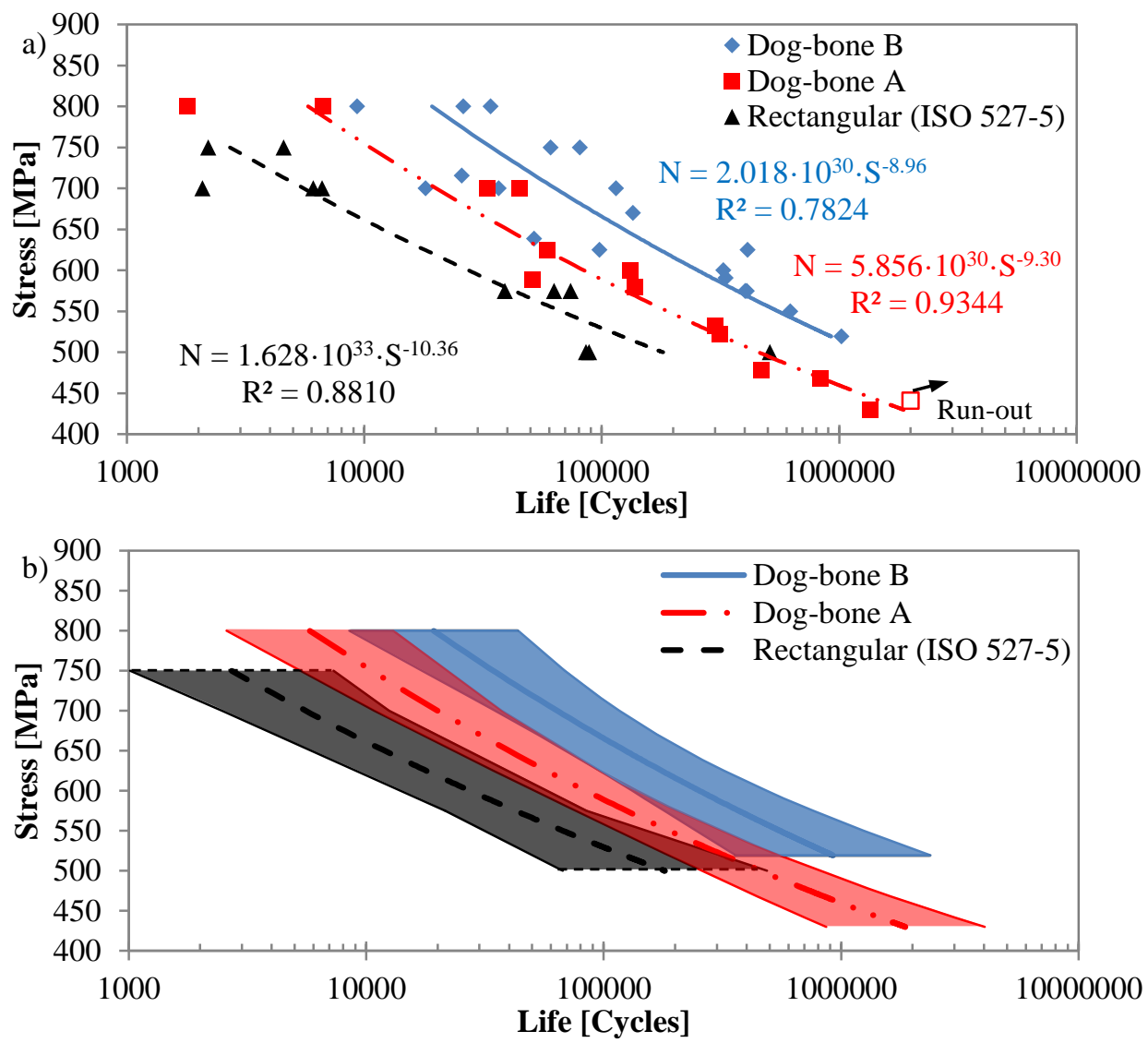

Figure 13. S-N curves a) without and b) with corresponding $95 \%$ confidence bands for the UD powder-bound fabric reinforced laminate, measured with the rectangular and dog-bone test specimens and tested with the stress ratio $\mathrm{R}=0.1$.

\subsubsection{Stitched fabric reinforced laminates}

S-N fatigue data of the stitched fabric reinforced laminates, measured with the rectangular and dogbone B specimens, are shown in Fig. 14. The results again show small $\mathrm{R}^{2}$ values for the rectangular specimen data and a slightly higher scatter for the dog-bone B specimens. The specified regression analysis indicated that the fatigue lives of both specimens are significantly different $(\mathrm{p}<0.001)$. The stress level corresponding to a fatigue life of $10^{4}$ cycles was $604 \mathrm{MPa}$ for the rectangular specimen and $656 \mathrm{MPa}$ for the dog-bone B specimen. 


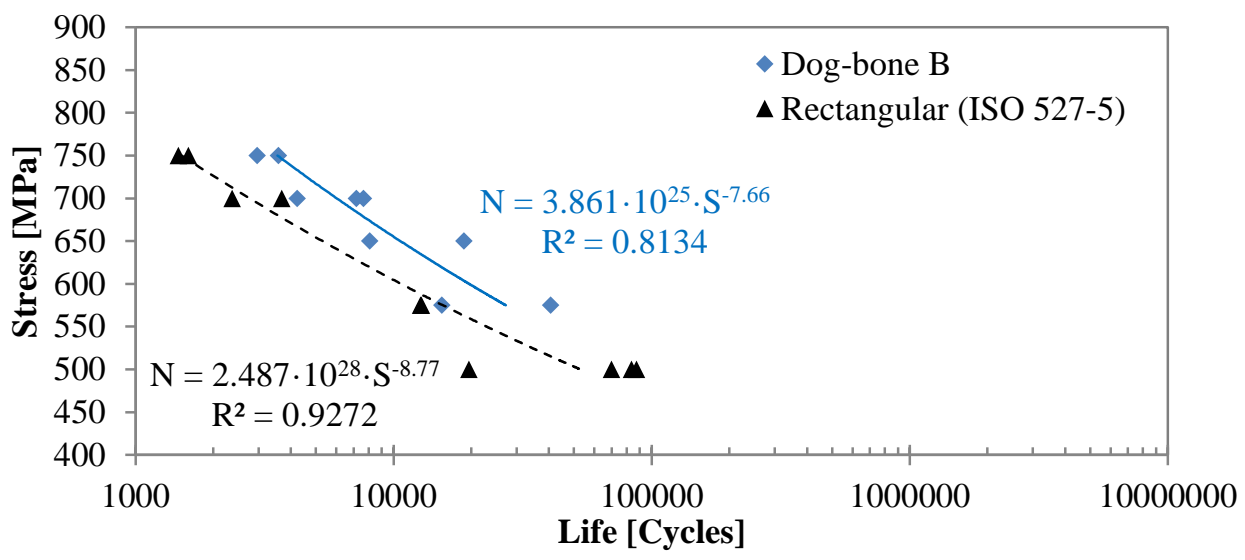

Figure 14. S-N curves for the stitched fabric reinforced laminate, measured with the rectangular and dog-bone $\mathrm{B}$ test specimens and tested with the stress ratio $\mathrm{R}=0.1$.

\subsubsection{Powder-bound versus stitched fabric reinforced laminates}

The fatigue data compiled for the powder-bound and stitched fabric reinforced laminates tested using the dog-bone B specimens is shown in Fig. 15. The results reveal that a $17 \%$ lower slope of the fitted S-N curve and over ten-fold fatigue life were measured for the powder-bound fabric reinforced laminate.

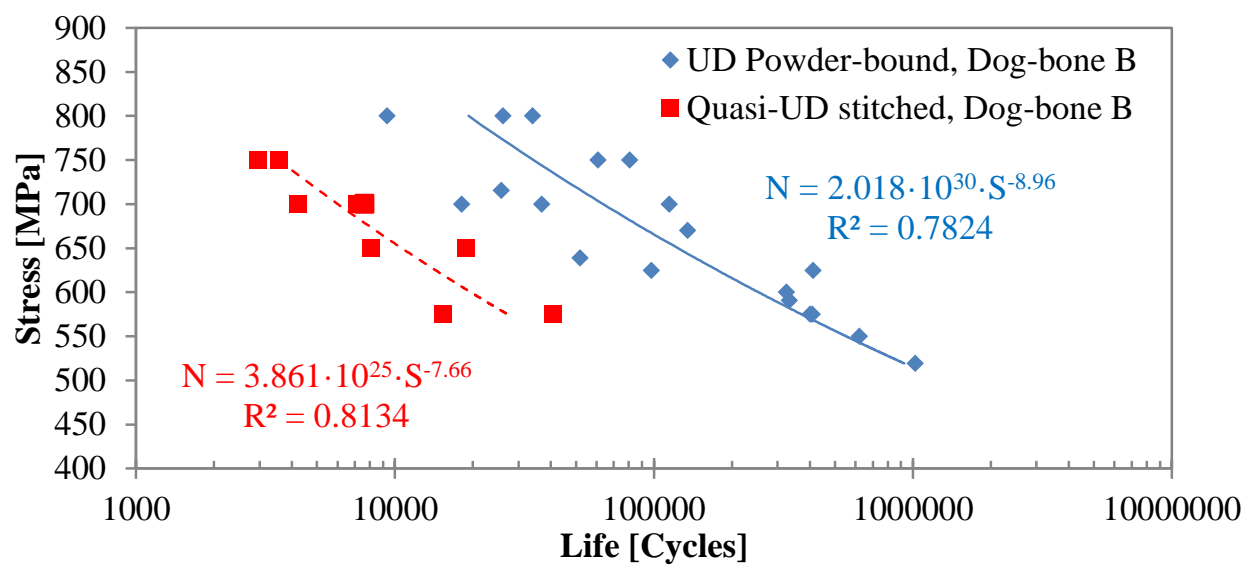

Figure 15. Comparison of the fatigue data for UD powder-bound fabric and quasi-UD stitched NCFreinforced laminates, measured using the dog-bone B specimens, tested with the stress ratio $\mathrm{R}=0.1$.

\subsection{Stiffness degradation}

Normalised stiffness degradation curves of the powder-bound fabric reinforced laminates measured in laboratory II during the fatigue tests of the dog-bone A and B specimens are shown in Fig. 16a and b, respectively. The dashed curves in Fig. 16a reveal that stiffness degradation did not occur in the gauge section of the dog-bone A specimens. The solid curves indicate that stiffness degraded, however, between the upper and lower grips, meaning that damages occurred outside the gauge section, i.e., in the tabbed area. The fall of some dashed curves in Fig. 16b indicates that some dog-bone B specimens experienced 
stiffness degradation in the gauge section, while the overall stiffness (solid curves) remained almost at the constant level till the final failure.
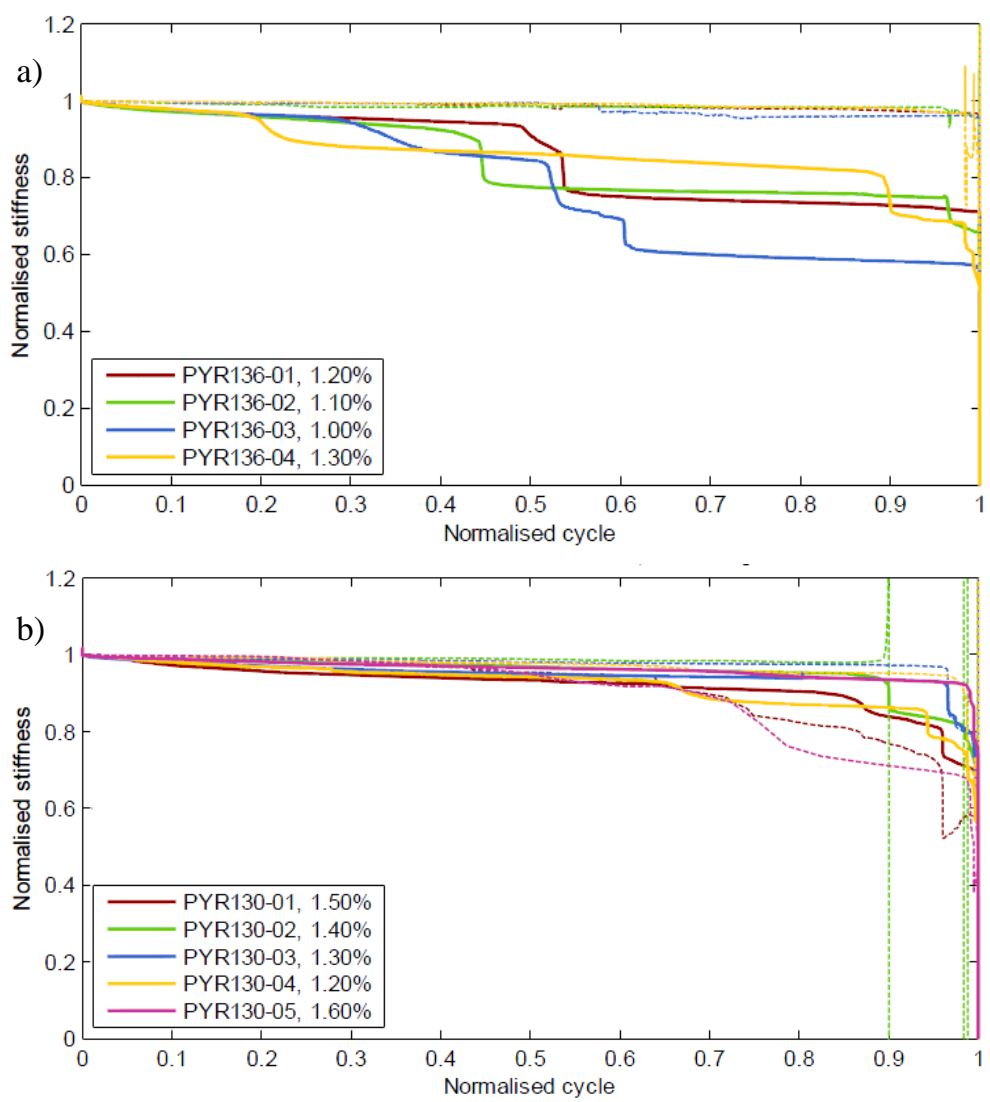

Figure 16. Normalised stiffness degradation curves of a) dog-bone A and b) dog-bone B specimens during the fatigue tests for the UD powder-bound fabric reinforced laminate. Dashed lines denote the average normalised stiffness degradation in the gauge section, and solid lines imply normalised stiffness degradation of the entire specimen measured between the lower and upper grips.

\section{Discussion}

\subsection{Effect of specimen type on fatigue behaviour}

The fatigue test results of this study showed that specimen type has a significant effect on the measured fatigue life (cycles) of UD and quasi-UD GFRP laminates. Each standard rectangular specimen failed in a catastrophic brittle manner at the tabs. This failure mode is common when testing UD GFRP laminates [11], [12], [13], [14]. The premature failure of these specimens was due to high local stress state. The computed stress concentration factor (SCF) for the longitudinal stress component was high and similar to that provided in current literature. De Baere [31] reported an SCF of 1.28 under the tabs of the rectangular specimen for carbon reinforced laminates - agreeing with the SCF of 1.32 that we computed for the rectangular specimen. 
The fatigue life of the powder-bound fabric reinforced laminate measured with the dog-bone A specimen was significantly higher than the fatigue life measured with the rectangular specimen, although the dog-bone specimens also failed frequently in the tab area, meaning that fatigue life measured with this specimen type is still conservative. The failure observations of the dog-bone A specimens were supported by the findings of the stiffness degradation measurements: there was no stiffness degradation in the gauge section but outside of that section there was.

The highest fatigue life for the powder-bound fabric reinforced laminate was measured with the dogbone B specimen. The fatigue life was significantly higher than that measured with the dog-bone A specimen, meaning that the measured life is much closer to the true life of the laminate, although some dog-bone B specimens also failed under the tabs. The highest stress concentration factor SCF of 1.02 is located next to the gauge section based on the FE-analysis as shown in Fig. 6. However, many of the specimens experienced damages in the gauge section, also leading to the specimen failure in the gauge section. Damage initiation points in the gauge section apparently contained some kind of defect(s), e.g., local fibre undulation or misalignment, or local manufacturing defects. As a consequence, these points were the weakest spots in terms of fatigue and lead to progressive damage accumulation in the gauge section (Fig. 8). The damages, associated heat development and stiffness degradation observed in the gauge section support the hypothesis that the final failure occurred in the gauge section for some dogbone B specimens.

For the stitched fabric reinforced laminate, all dog-bone B specimens experienced damages in the gauge section and seemed to fail in the gauge section. In consequence, the fatigue life measured with the dog-bone B specimen was significantly higher than the fatigue life measured with the rectangular specimen. In the stitched fabric reinforced laminate, backing bundles, stitch threads and fibre undulation due to stitching and backing bundles result in weak spots which act as damage initiators. These damages have time to initiate and develop prior to the detrimental damages occurred in the tabbed area. The fatigue test results are supported by the investigation in ref. [14], in which a waisted test specimen yielded a slightly higher fatigue life than the rectangular specimen for a quasi-UD laminate reinforced by stitched NCF. However, in that study the specimens were subjected only to one stress level and they seldom failed in the gauge section. 
When comparing results obtained with the dog-bone A and B specimens, it seems that relatively small changes in the specimen geometry, i.e., lower curvature, longer end tab taper and shorter spacing of end tabs reduce shear stresses and the area with high shear stress, thus restraining longitudinal splitting and delamination between the laminate and tabs. These small changes in the dog-bone B specimen geometry delayed the damages at the tabbed area, resulting in higher fatigue lives. Therefore, damages had also time to initiate and grow in the gauge section of some dog-bone B specimens. The results of the FEanalysis indicated that the SCF and the transverse stresses are almost similar for both dog-bone specimens. Thus, the observed differences in the failure development and fatigue performance between the dog-bone specimens can be explained at least partly by the difference in shear stresses occurring at the specimen edges. Different end tab laminate constituents, adhesives used for end tab bonding and manufacturing procedures of the specimens obviously also contribute to the specimen performance.

\subsection{Effect of reinforcement type on fatigue performance}

The measured fatigue life of the powder-bound fabric reinforced laminate was significantly higher than the life of the stitched fabric reinforced laminate. A lower slope of the fitted S-N curve was also found for the laminate reinforced with powder-bound fabrics when compared to its stitched counterpart. One obvious reason for the better fatigue performance provided by the powder-bound fabric is the improved fibre alignment resulting from an absence of backing fibres and stitching. Stitching and backing bundles have been found to cause fibre undulation [5], which weakens fatigue performance [1]. The fatigue test results of this study are supported by the investigations in ref. [15], in which the influence of the stitching thread was studied. The researchers found that removing the stitching from the UD fabrics before infusion improved fatigue life and lowered the slope of the fitted S-N curve. In ref. [22], researchers studied the influence of the presence of backing bundles in quasi-UD NCFs. They observed that fatigue lives improved significantly for polyester laminates, but only slightly for epoxy laminates without backing bundles. The minor improvement obtained with epoxy laminates may be due to the rectangular specimens used in the study. Zangenberg et al. in ref [23] showed that the backing bundles of UD laminates act as damage initiators and may be the reason for a lower life time.

\subsection{Interpretation of the fatigue life}

The standard interpretation of materials' fatigue performance is the graph of S-N curves, where the stress is given as the nominal stress emerging in the test specimen gauge section. An interesting 
comparison between the test specimens of this study can be done by plotting the fatigue lives per highest stress peak (i.e., the stresses in the gauge section in Fig. 13a are multiplied by the peak SCF shown in Fig. 6). Then, the fatigue performances of the laminates are similar for the rectangular and dog-bone B specimens but much lower for the dog-bone A specimen (see Fig. 17).

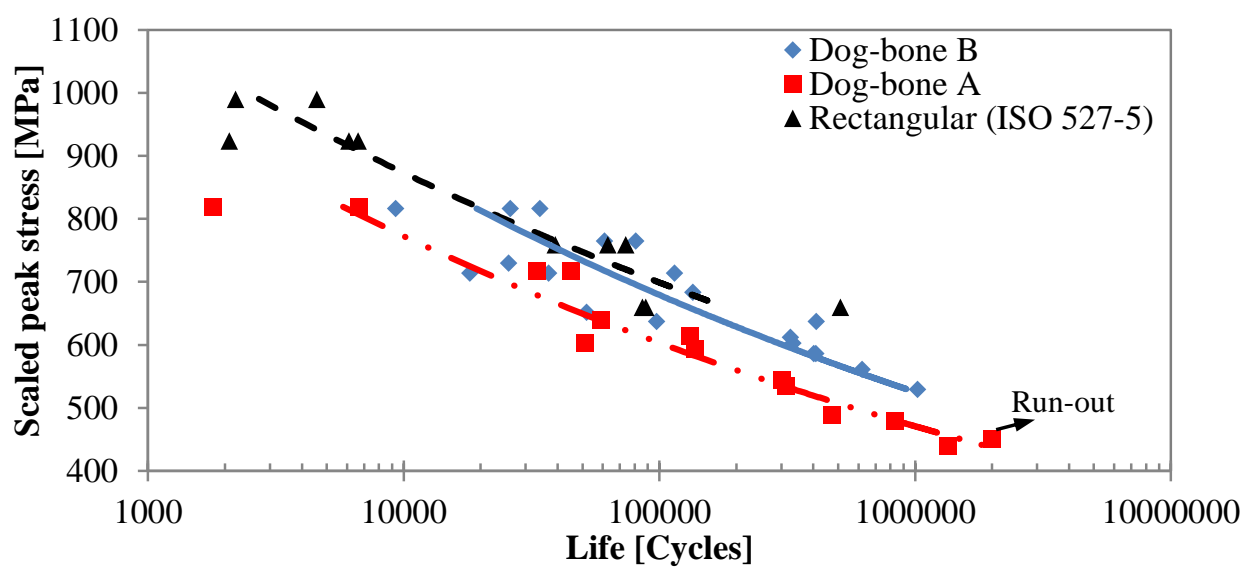

Figure 17. Scaled S-N curves by stress concentration factors SCF for rectangular and dog-bone specimens.

Although the comparison might sound justified per specimen type, it has the following major complications:

- Fatigue testing and S-N curves per nominal stress emerging in the test specimen gauge section are a highly established custom - a change in the custom would make any cross-comparison between material data difficult.

- Here, the fatigue lives under pure tensile loading were considered. The point of peak stress concentration, especially for the rectangular specimen, is a more complex load state.

The determination of a proper 'peak' stress concentration would depend on the selected (stress) criterion (e.g., Hashin-Rotem [32] due to anisotropy) and its calculation method. Moreover, the selected criterion should be applicable for the length scale of defects which in reality initiate the fatigue damage. Therefore, a test specimen with a stress concentration near or at the gauge section, and the stress concentration peak emerging close to the targeted load state, should give the most valid results in practical testing. In this respect, the dog-bone B specimen surpasses the other two specimens of this study. 


\section{Conclusions}

The aim of this study was to define a suitable specimen configuration for uni-axial tension-tension fatigue testing of UD GFRP laminates. The aim was also to compare the tensile fatigue behaviour of glass-fibre/epoxy laminates reinforced with a newly developed UD powder-bound fabric and with a quasi-UD stitched non-crimped fabric. Three different specimens, a rectangular specimen in accordance with the ISO 527-5 standard and two dog-bone shaped specimens were first evaluated by means of FE analyses. Subsequent tensile fatigue tests were performed to compare the fatigue performance of the specimens. The fatigue performance was clearly dependent on the specimen geometry. The study revealed that the rectangular specimen yields significantly lower fatigue lives when compared to the fatigue lives measured with the dog-bone specimens. In addition, the dog-bone B specimen with longer end tab taper, lower curvature, shorter distance of end tabs and different tabbing yielded significantly higher fatigue lives than the dog-bone A specimen.

The final failure of the rectangular specimen occurred at the end tabs with both types of laminates, meaning that the fatigue performance of the laminates is underestimated. Also, when testing the UD powder-bound fabric reinforced laminate, all dog-bone A and some dog-bone B specimens experienced longitudinal splitting at the edges and delamination of the laminate and end tab joint, which resulted in the final failure at the end tab area. However, many dog-bone B specimens experienced damages in the gauge section and seemed to fail in the gauge section. Also, for the laminate reinforced with the stitched fabric, all dog-bone B specimens seemed to fail in the gauge section. According to the FE analysis results, the peak shear stress is higher and the area with high shear stress is larger in the dog-bone A specimen when compared to the dog-bone B specimen. There were also differences in end tab materials, adhesives and manufacturing procedures of the specimens. Thus, the combination of lower shear stresses, different end tab materials, adhesives and manufacturing procedures of the dog-bone B specimens delayed the damages in the tabbed area resulting in higher fatigue lives for the dog-bone B specimens.

With regard to the fatigue performance comparison of the laminates reinforced with the UD powderbound fabrics and quasi-UD stitched NCFs, the fatigue life of the former was measured to be over ten times greater when the dog-bone B specimen was used. In addition, a lower slope of the fitted S-N curve was found for the benefit of the powder-bound fabric reinforced laminate. 


\section{Acknowledgements}

This work was funded by the Finnish Funding Agency for Technology and Innovation (TEKES) through the FIMECC Light project. The authors gratefully acknowledge the personnel of Ahlstrom Glassfibre Oy for their assistance in the research. D.Sc. (Tech.) Mikko Kanerva is also acknowledged for his help.

\section{References}

[1] Vallons K, Adolphs G, Lucas P, Lomov SV, Verpoest I. Quasi-UD glass fibre NCF composites for wind energy applications: a review of requirements and existing fatigue data for blade materials. Mechanics \& Industry, 2013; 14(03):175-189. http://dx.doi.org/10.1051/meca/2013045

[2] Lekakou C, Edwards S, Bell G, Amico SC. Computer modelling for the prediction of the in-plane permeability of non-crimp stitch bonded fabrics. Composites Part A: Applied Science and Manufacturing 2006;37(6):820-825. http://dx.doi.org/10.1016/j.compositesa.2005.04.002

[3] Korkiakoski S, Haavisto M, Rostami Barouei M, Saarela O. Experimental compaction characterization of unidirectional stitched non-crimp fabrics in the vacuum infusion process. Polymer Composites 2015. http://dx.doi.org/10.1002/pc.23464

[4] Bibo GA, Hogg PJ, Kemp M. Mechanical characterisation of glass- and carbon-fibrereinforced composites made with non-crimp fabrics. Composites Science and Technology 1997;57(9):1221-1241. http://dx.doi.org/10.1016/S0266-3538(97)00053-5

[5] Mattsson D, Joffe R, Varna J. Methodology for characterization of internal structure parameters governing performance in NCF composites. Composites Part B: Engineering 2007;38(1):44-57. http://dx.doi.org/10.1016/j.compositesb.2006.04.004

[6] Bergström R. A unidirectional reinforcement and a method of producing a unidirectional reinforcement. EP patent EP2687356 A1. 2014.

[7] Kensche CW (ed). Fatigue of materials and components for wind turbine rotor blades. EUR 16684, European Commission, Luxembourg, 1996.

[8] Brøndsted P, Lilholt H, Lystrup A. Composite materials for wind power turbine blades. Annu. Rev. Mater. Res. 2005;35:505-538. http://dx.doi.org/10.1146/annurev.matsci.35.100303.110641

[9] Vallons K, Adolphs G, Lucas P, Lomov SV, Verpoest I. The influence of the stitching pattern on the internal geometry, quasi-static and fatigue mechanical properties of glass fibre non-crimp fabric composites. Composites Part A: Applied Science and Manufacturing 2014; 56: 272-279. http://dx.doi.org/10.1016/j.compositesa.2013.10.015

[10] Kensche CW. Fatigue of composites for wind turbines. International Journal of Fatigue 2006; 28(10):1363-1374. http://dx.doi.org/10.1016/j.ijfatigue.2006.02.040

[11] Mandell JF, Reed RM, Samborsky DD, Pan Q. Fatigue performance of wind turbine blade composite materials. Wind Energy 1993; 14:191-198.

[12] Mandell JF, Reed RM, Samborsky DD. Fatigue of fiberglass wind turbine blade materials. Sandia National Laboratories, 1992.

[13] Nijssen RPL. Fatigue Life Prediction and Strength Degradation of Wind Turbine Rotor Blade Composites. Delft University of Technology, 2006.

[14] Zangenberg J. The effects of fibre architecture on fatigue life-time of composite materials. Technical University of Denmark. DTU Wind Energy PhD-0018 (EN). September 2013. 
[15] Mandell JF, Samborsky DD. DOE/MSU composite material fatigue database: test methods, materials, and analysis. Sandia National Labs, Albuquerque, NM (United States), 1997.

[16] Optimat Blades Project, data and publications available from: http://wmc.eu/optimatblades.php

[17] Qian C. Multi-scale modelling of fatigue of wind turbine rotor blade composites. Delft University of Technology, 2013.

[18] Aono Y, Hirota K, Lee SH, Kuroiwa T, Takita K. Fatigue damage of GFRP laminates consisting of stitched unit layers. International Journal of Fatigue 2008; 30(10):1720-1728. http://dx.doi.org/10.1016/j.ijfatigue.2008.03.002

[19] Owens Corning. Advantex ${ }^{\circledR}$ product data sheet. Available from: http://www.ocvreinforcements.com/pdf/library/Advantex_ECR_glass_properties_ww_2010 04_web.pdf

[20] Plastics - Determination of tensile properties - Part 5: Test conditions for unidirectional fibre-reinforced plastic composites. EN ISO 527-5:2009.

[21] Crompton TR. Thermal Methods of Polymer Analysis. Smithers Rapra Technology. 2013.

[22] Samborsky DD, Mandell JF, Miller D. The SNL/MSU/DOE fatigue of composite materials database: Recent Trends. In: 53rd AIAA/ASME/ASCE/AHS/ASC Structures, Structural Dynamics and Materials Conference 20th AIAA/ASME/AHS Adaptive Structures Conference 14th AIAA. 2012.

[23] Zangenberg J. Brøndsted P. Gillespie Jr JW. Fatigue damage propagation in unidirectional glass fibre reinforced composites made of a non-crimp fabric. Journal of Composite Materials 2014;48(22): 2711-2727. http://dx.doi.org/10.1177/0021998313502062

[24] EsaComp 4.3 - Software for analysis and design of composites from Componeering Inc. 2014.

[25] Fibre reinforced plastics - determination of fatigue properties under cyclic loading conditions. ISO 13003:2003.

[26] Harris B. Fatigue in composites: science and technology of the fatigue response of fibrereinforced plastics. Cambridge: Woodhead Publishing, 2003.

[27] Vassilopoulos AP, Keller T. Fatigue of fiber-reinforced composites. Springer Science \& Business Media, 2011.

[28] ASTM E 739-91. Standard practice for statistical analysis of linear or linearized stress-life $(\mathrm{S}-\mathrm{N})$ and strain-life $(\varepsilon-\mathrm{N})$ fatigue data. ASTM International, West Conshohocken, PA; 2004.

[29] Minitab 17, Statistical Software for Windows from Minitab Inc. 2014.

[30] HANDBOOK, Military. MIL-HDBK-5H: Metallic Materials and Elements for Aerospace Vehicle Structures. US Department of Defense, 1998.

[31] De Baere I, Van Paepegem WV, Degrieck J. On the design of end tabs for quasi-static and fatigue testing of fibre-reinforced composites. Polymer Composites 2009; 30(4): 381-390. http://dx.doi.org/10.1002/pc.20564

[32] Hashin Z, Rotem A. A fatigue failure criterion for fibre-reinforced materials. Journal of Composite Materials 1973; 7(4): 448-464. http://dx.doi.org/10.1177/002199837300700404 